\title{
Dendritic targeting of short and long 3' UTR BDNF mRNA is regulated by BDNF or NT-3 and distinct sets of RNA-binding proteins
}

\author{
Annalisa Vicario', Andrea Colliva' ${ }^{1}$ Antonia Ratti2,3, Laetitia Davidovic4, Gabriele Baj', \\ Łukasz Gricman', Claudia Colombrita ${ }^{2,3}$, Alberto Pallavicini', Kevin R. Jones ${ }^{5}$, \\ Barbara Bardoni4 and Enrico Tongiorgi ${ }^{1 *}$

\begin{abstract}
${ }^{1}$ Department of Life Sciences, University of Trieste, Trieste, Italy, ${ }^{2}$ Laboratory of Neuroscience - IRCCS Istituto Auxologico Italiano, Milano, Italy, ${ }^{3}$ Department of Pathophysiology and Transplantation, "Dino Ferrari Center", Università degli Studi di Milano, Milano, Italy, ${ }^{4}$ INSERM, IPMC - CNRS, UMR 7275, Valbonne, France, ${ }^{5}$ Department of Molecular Cellular and Developmental Biology, University of Colorado, Boulder, CO, USA
\end{abstract}

\section{OPEN ACCESS}

Edited by:

Jean-Marc Taymans, Jean-Pierre Aubert Research Center,

France

Reviewed by:

Nicole Déglon,

Lausanne University Hospital,

Switzerland

Carlos B. Duarte,

University of Coimbra, Portugal

\section{${ }^{*}$ Correspondence: \\ Enrico Tongiorgi \\ tongi@units.it}

Received: 09 April 2015 Accepted: 12 October 2015 Published: 29 October 2015

Citation

Vicario A, Colliva A, Ratti A, Davidovic L, Baj G, Gricman , Colombrita $C$, Pallavicini A, Jones $K R$, Bardoni B and Tongiorgi E (2015) Dendritic targeting of short and long $3^{\prime}$ UTR BDNF MRNA is regulated by BDNF or NT-3 and distinct sets

of RNA-binding proteins.

Front. Mol. Neurosci. 8:62. doi: 10.3389/fnmol.2015.00062
Sorting of mRNAs in neuronal dendrites relies upon inducible transport mechanisms whose molecular bases are poorly understood. We investigated here the mechanism of inducible dendritic targeting of rat brain-derived neurotrophic factor (BDNF) mRNAs as a paradigmatic example. BDNF encodes multiple mRNAs with either short or long 3' UTR, both hypothesized to harbor inducible dendritic targeting signals. However, the mechanisms of sorting of the two $3^{\prime}$ UTR isoforms are controversial. We found that dendritic localization of BDNF mRNAs with short $3^{\prime}$ UTR was induced by depolarization and NT3 in vitro or by seizures in vivo and required CPEB-1, -2 and ELAV-2, -4. Dendritic targeting of long $3^{\prime}$ UTR was induced by activity or BDNF and required CPEB-1 and the relief of soma-retention signals mediated by ELAV-1, -3, -4, and FXR proteins. Thus, long and short $3^{\prime}$ UTRs, by using different sets of RNA-binding proteins provide a mechanism of selective targeting in response to different stimuli which may underlay distinct roles of BDNF variants in neuronal development and plasticity.

Keywords: neurotrophins, brain-derived neurotrophic factor, dendrites, hippocampus, RNA transport, RNA binding proteins, Fragile- $X$

\section{INTRODUCTION}

Subcellular compartmentalization of mRNAs is a mechanism enabling local synthesis of proteins required for neuronal development and plasticity such as brain-derived neurotrophic factor (BDNF; Tongiorgi et al., 1997; Steward and Schuman, 2001; Soule et al., 2006; Rodriguez et al., 2008; Tongiorgi, 2008; Martin and Ephrussi, 2009). Although BDNF mRNA abundance in dendrites is generally low, dendritic localization is enhanced in response to membrane depolarization (Tongiorgi et al., 1997) or to BDNF itself (Righi et al., 2000). Evidence that $B D N F$ mRNA translation can occur in dendrites was provided by studies ex vivo using neurosynaptosomes (Raju et al., 2011; Gharami and Das, 2014) and in vitro in hippocampal neurons (An et al., 2008; Verpelli et al., 2010; Baj et al., 2011). The mechanism underlying BDNF mRNA targeting to dendrites is poorly understood, partly because of the complexity of $B D N F$ gene regulation (Figure 1A, upper panel). Transcription of rodent $B D N F$ gene produces 11 transcripts, each with a different alternatively spliced $5^{\prime}$ untranslated region ( $5^{\prime}$ UTR) and the same coding 


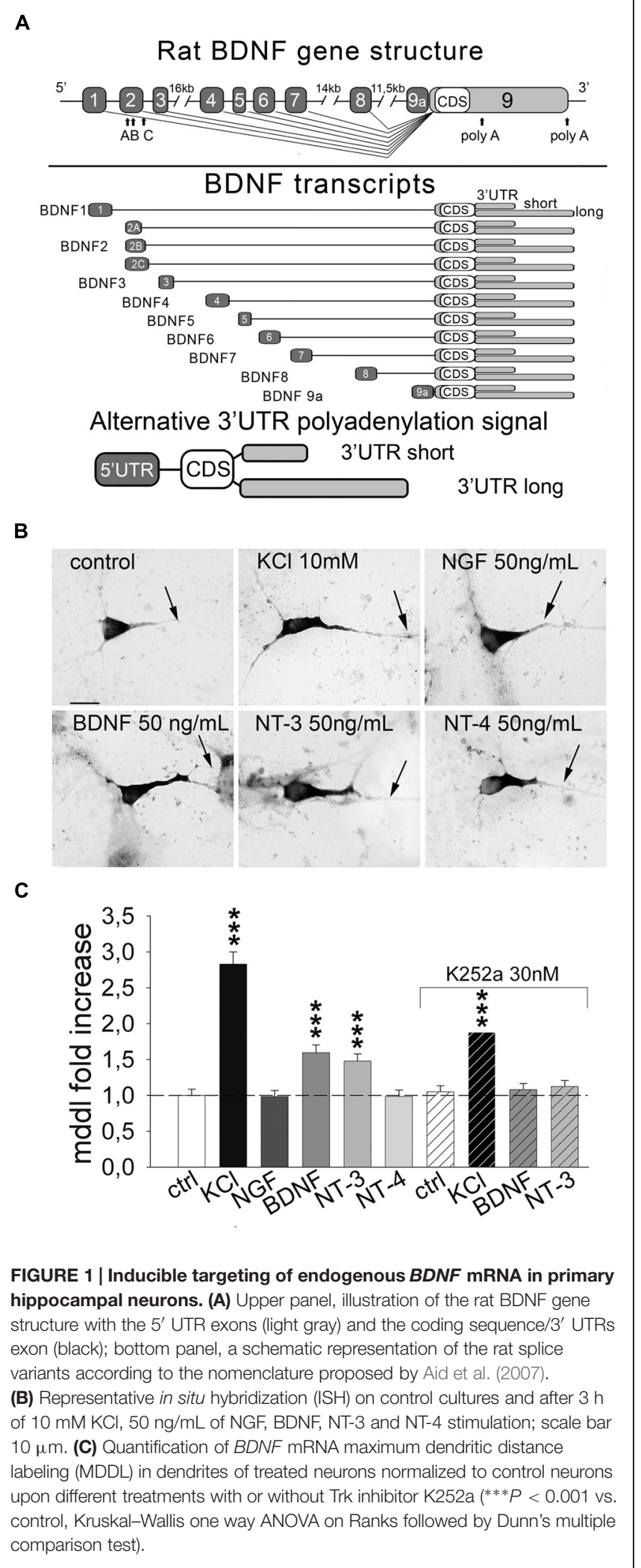

region (CDS; Figure 1A; Aid et al., 2007; Pruunsild et al., 2007). These transcripts can exist in two isoforms, either with long
(3.2 Kb) or short $(0.3 \mathrm{~Kb}) 3^{\prime}$ UTR (Figure 1A, bottom panel; Aid et al., 2007; Pruunsild et al., 2007). There is general consensus that most $B D N F$ transcripts are restricted to the soma and proximal dendrites (e.g., exons 1, 4) but selected variants are transported distally (e.g., exons 2,6 ) in an activity-dependent manner (An et al., 2008; Chiaruttini et al., 2008, 2009; Aliaga et al., 2009; Baj et al., 2013; Will et al., 2013).

To explain the mechanism of BDNF transcripts' sorting, two alternative models were proposed. The first is a dualistic mechanism by which somatic BDNF transcripts express the short 3' UTR while dendritic transcripts have the long $3^{\prime}$ UTR (An et al., 2008). However, in rodent brain models, transcripts containing exons 1,2 , 4, and 6 (formerly I, II, III, IV) are expressed with long or short $3^{\prime}$ UTR in a 1:1 ratio and, after kainic acid-induced seizures, transcripts having mainly the short 3' UTR are detected (Timmusk et al., 1993). Remarkably, following seizures, exons 2 and 6 were detected in distal dendrites (Chiaruttini et al., 2008; Baj et al., 2013). Our alternative model is based on a tripartite combinatorial mechanism in which "selector" signals are located in the $5^{\prime}$ UTR (for dendrite or soma destination), a constitutively active dendritic targeting element (DTE) mediated by Translin in the CDS, and activity-dependent DTEs harbored in both long and short $3^{\prime}$ UTRs (Pattabiraman et al., 2005; Chiaruttini et al., 2008, 2009; Aliaga et al., 2009; Baj et al., 2011, 2013). In support of this model, BDNF mRNAs with either $3^{\prime}$ UTRs were shown to be transported in dendrites in response to neural activity (Oe and Yoneda, 2010; Baj et al., 2011). Activity-dependent dendritic targeting of the $3^{\prime}$ UTR short requires the RNA-binding protein (RBP) CPEB-1 (Oe and Yoneda, 2010) while the targeting mechanism of the $3^{\prime}$ UTR long was not investigated. Here, we investigated the dendritic targeting mechanism of BDNF transcripts with long or short $3^{\prime}$ UTR, demonstrating selective induction by BDNF or NT-3, respectively thanks to interactions with distinct sets of RBPs.

\section{MATERIALS AND METHODS}

\section{Chimaeric GFP Constructs}

Total RNA was extracted from whole rat brain using TriZol ${ }^{\circledR}$ Reagent (Invitrogen). $1 \mu \mathrm{g}$ of total RNA was reverse-transcribed into cDNA and amplified with specific primer pairs. For details on BDNF CDS-GFP chimera cloning (please see, Chiaruttini et al., 2009). PCRs were performed with Phusion Hi-Fidelity DNA polymerase (New England BioLabs) using specific primer pairs and PCR conditions (reported in Supplementary Table S1). A direct amplification and cloning in pEGFP-N1 vector (Clontech) was performed for BDNF $3^{\prime}$ UTRshort, $3^{\prime}$ UTRshortmutELAV-up, $3^{\prime}$ UTRlong, $3^{\prime}$ UTRmid and $3^{\prime}$ UTRend. For $3^{\prime}$ UTRshort-mutCPE and $3^{\prime}$ UTRshort-mutELAV-dw cloning, an assembly strategy was adopted. Briefly a first round of PCR was performed using the primer pairs for CPE and ELAV$\mathrm{dw}$ mutations (Supplementary Table S1). The second round of PCR was performed using CPE and ELAV-dw mutant fragments obtained in the first round as forward "megaprimers" with $3^{\prime}$ UTRsh reverse primer to obtain mutated full length $3^{\prime}$ UTR short sequences. PCR fragments were then purified (PCR 
Cleanup kit from Sigma-Aldrich) and digested with XhoI/SacII for BDNF coding sequence or NotI/HpaI for $3^{\prime}$ UTRs mutants. All restriction enzymes were purchased from New England BioLabs. Digested fragments were gel purified (PCR Gene Elute kit from Sigma-Aldrich) and ligated (T5 DNA ligase from New England BioLabs) over night at $16^{\circ}$ with properly digested pEGFP-N1 vector.

\section{Protocol for CLIP}

The CLIP (cross-linking and immunoprecipitation) assay for ELAV was performed as previously described by Ratti et al. (2006) and for FMRP was carried out using brains lysates from wild type (WT) and Fmr1-KO mice as described by Davidovic et al. (2011). Radiolabeled riboprobes for BDNF $3^{\prime}$ UTR sequences were obtained by transcribing pBluescript KS containing BDNF $3^{\prime}$ UTR short, $3^{\prime}$ UTR mid, and $3^{\prime}$ UTR end sequences. Oligos and conditions used for BDNF coding sequence Reverse transcriptase-PCR on CLIP are reported in Supplementary Table S1. PCR oligos and conditions used for Pgk1 and Map1b were previously described by Edbauer et al. (2010).

\section{Bioinformatic Analysis}

Analysis of evolutionary conserved regions in BDNF CDS and $3^{\prime}$ UTRs was performed using phastCons alignment software (Siepel et al., 2005). The research of putative cis-elements for RBPs on rat BDNF $3^{\prime}$ UTR sequence was performed using Bioedit software (http://www.mbio.ncsu.edu/BioEdit/bioedit.html). The RNA motifs reported in literature for the cited RBPs were pairwise aligned on the target sequence and at least $80 \%$ homology was set as threshold to define a putative cis-element.

\section{RNAi Interference}

RNAi interference (RNAi) "cocktails" against the different RBPs were generated by RNAseIII (Ambion) cleavage of relatively long ( $\sim 300 \mathrm{nt})$ double-stranded RNA. Target regions of mRNA encoding for RBPs were identified by consulting the NCBI data base. To amplify the target regions, oligonucleotidic primers containing the T7 promoter were used to amplify the target regions and produce siRNA following manufacturer instructions. Sequences and protocol are reported in Supplementary Table S2. In order to evaluate RNAi "cocktails" efficacy and specificity, reverse transcriptase PCR was performed on RNA extracted from primary hippocampal cultures of rat neurons. To amplify the targeted mRNAs we used oligonucleotidic primers containing the same sequence designed for siRNA pools generation. Sequences and protocol are reported in Supplementary Table S2. For quantification, PCR bands were scanned and quantified by the Quantity One ${ }^{\circledast}$ 4.6.6. software (Bio-Rad, Hercules, CA, USA).

\section{Cell Cultures}

Primary rat and mouse hippocampal neurons were prepared from P0 pups as previously described (Tongiorgi et al., 1997) with slight modifications. Cells were plated on 2\% Matrigel (BD Biosciences) coated coverslips in 24-well plates at a density of
$2 \times 10^{5}$ cells per well and cultured for 6 days in neurobasal supplemented with B27 (Invitrogen) and pen/strep in a 5\% $\mathrm{CO}_{2}$-humidified incubator. The medium was changed every 2 days from the second day in culture onward. PC12 rat pheochromocytoma cells, used to asses RBP siRNAs efficiency and specificity, were cultured in RPMI medium supplemented with 10\% FBS, 5\% Donor Horse Serum, 2 mM L-glutamine, $20 \mathrm{mM}$ Hepes and antibiotics (Euroclone) and differentiated in DMEM containing $1 \%$ horse serum, $1 \%$ Pen-Strep, and $50 \mathrm{ng} / \mathrm{ml}$ NGF (Sigma). Cells were transfected with Lipofectamine $2000^{\mathrm{TM}}$ (Invitrogen) with $1 \mu \mathrm{g}$ of plasmid DNA or $19 \mathrm{nM}$ of siRNA mixture (at 6 DIV for neurons or $75 \%$ confluency for PC12 cells). Neurons were depolarized as previously described (Tongiorgi et al., 1997), or treated with different neurotrophins (BDNF, NT-3, NT-4; SIGMA) at a $50 \mathrm{ng} / \mathrm{mL}$ concentration in culture medium. After $3 \mathrm{~h}$ of depolarization or neurotrophin administration, cells were fixed with PFA $4 \%$ for 15 ' at RT.

\section{Animal Treatment}

Animals were treated according to the institutional guidelines in compliance with the European Council Directive 86/609 and NIH Guide for the Care and Use of Laboratory Animals. Animal experiments on $\mathrm{WT}$ and $\mathrm{BDNF}$ lox/lox mice were authorized by the Italian Ministero della Salute n. 185/2010-B d.d. 21/10/2010. Two month old male C57/BL6 or BDNF ${ }^{\text {lox/lox }}$ mice (Gorski et al., 2003) were anesthetized with urethane ( $1 \mathrm{~g} / \mathrm{kg}$, i.p.) $30 \mathrm{~min}$ prior to i.p. injection of $300 \mathrm{mg} / \mathrm{kg}$ pilocarpine or saline. Animals were housed in groups under standard animal room conditions (12:12 h light/dark cycle, ambient temperature $23^{\circ} \mathrm{C}$, ad libitum access to food and water).

\section{In situ Hybridization and Fluorescent In situ Hybridization}

In situ hybridization (ISH) on brain sections or cultures was performed as previously described (Tongiorgi et al., 1997, 1998). Cells were fixed for $15 \mathrm{~min}$ at RT in 4\% PFA in PBS, washed in PBST, and permeabilized in absolute ethanol for $15 \mathrm{~min}$ at $-20^{\circ} \mathrm{C}$. After rehydration, cells were hybridized with antisense or sense probes for GFP mRNA or BDNF CDS. The open reading frame of GFP or BDNF CDS were subcloned into pBluescript or pGEM vectors respectively and DIG- labeled probes were synthesized with the DIG-RNA labeling kit (Roche Diagnostics) using linearized plasmids as templates, according to the manufacturer's instructions. Hybridization was followed by high stringency washes with $0.01 x$ Sodium Saline Citrate buffer containing $0.1 \%$ Tween 20 (SSCT) at $60^{\circ} \mathrm{C}$, then coverslips were incubated with anti-digoxigenin alkaline phosphatase coupled antibody and developed with NBT and BCIP for $40 \mathrm{~min}$ at RT. For fluorescent in situ hybridization (FISH) after PFA fixation cells were incubated with $\mathrm{H}_{2} \mathrm{O}_{2} / \mathrm{PBS} \quad 0.3 \%$ for endogenous peroxydase quenching and then permeabilized with EtOH. After probe hybridization and stringency washes, coversplis were incubated with anti-digoxigenin horse-radish peroxidise conjugated (Roche) diluted 1:300 in blocking solution at RT for $1 \mathrm{~h}$. HRP detection was performed using Tyramide System Amplification kit - Cyanin 3 coupled (Perkin Elmer) following 
manufacturer instructions. After three washes in TNT buffer, cells were incubated with the primary antibodies against different RBPs diluted in PBST/FBS 5\% (Supplementary Table S3). Nuclei were stained with Hoechst 33342 and the coverslips were mounted with Mowiol (Sigma). ISH on free-floating, $40 \mu \mathrm{m}$ coronal sections cut at the level of dorsal hippocampus was performed as previously described (Tongiorgi et al., 1997, 1998). After permeabilization, sections were pre-hybridized at $55^{\circ} \mathrm{C}$ for $1 \mathrm{~h}$ followed by an overnight incubation at $55^{\circ} \mathrm{C}$ with $100 \mathrm{ng} / \mathrm{mL}$ BDNF CDS antisense probe. ISH was stained with the fluorescent anti-DIG enhancer set (Roche diagnostics), following manufacturer's instructions. Sections were mounted in anti-fade mounting solution (Invitrogen) and stored at $4^{\circ} \mathrm{C}$ in dark.

Confocal images of FISH on brain slices were acquired by a Nikon Eclipse C1si confocal system mounted on a Nikon TE-2000U inverted microscope. We used a Plan-Apochromat $20 \mathrm{x} / 0.75$ (NA) and $60 \mathrm{x} / 1.4(\mathrm{NA})$ oil-immersion objectives. The resolution used was of $0.2 \mu \mathrm{m} \times 0.2 \mu \mathrm{m} \times 0.5 \mu \mathrm{m}(\mathrm{XxYxZ})$ for 20X acquisitions and $0.08 \mu \mathrm{m} \times 0.08 \mu \mathrm{m} \times 0.25 \mu \mathrm{m}(\mathrm{XxYxZ})$ for $60 \mathrm{X}$ acquisitions. To obtain comparable signals between control and treated conditions, confocal images were acquired keeping the same acquisition settings for laser intensity, pmt amplification, pinhole aperture $(33 \mu \mathrm{m})$ and pixel dwell $(0.48 \mu \mathrm{s})$.

\section{Immunohistochemistry}

Brain-derived neurotrophic factor immunohistochemistry on WT and $\mathrm{BDNF}^{\mathrm{lox} / \mathrm{lox}}$ brain sections were performed on $2 \%$ PFA perfused brains cut at $40 \mu \mathrm{m}$ thick coronal sections, as previously described (Tongiorgi et al., 2004). Slices were developed through Nickel-enhanced diamminobenzidine (DAB) chromogenic reaction for about 20-30 min at room temperature in dark. All passages, except development, were performed in gentle shaking.

\section{Western Blots}

Cells were collected in lysis buffer and the lysates were centrifuged at $10000 \mathrm{rpm}$ for $15 \mathrm{~min}$ at $10^{\circ} \mathrm{C}$ to remove cellular debris. Protein concentration was determined using Bradford assay. Samples were resolved on 12\% SDS-PAGE gels, loading $20 \mu \mathrm{g}$ of PC12 extracts. Proteins were transferred onto nitrocellulose membrane (Schleicher\&Schuell) and stained using the different antibodies (Supplementary Table S3). Membranes were then washed $3 \mathrm{~min} \times 5 \mathrm{~min}$ in $5 \%$ non fat milk in PBST and incubated for $1 \mathrm{~h}$ at RT with the respective secondary antibody (Supplementary Table S3) and membrane developed with chemiluminescent substrate (ECL by GE Healthcare). X-ray films were scanned and quantified by the Quantity One ${ }^{\circledR}$ 4.6.6. software (Bio-Rad, Hercules, CA, USA).

\section{Colocalization Analysis}

Confocal images were acquired by a Nikon Eclipse C1 confocal microscope mounted on a Nikon TE-2000U inverted microscope using a Plan-Apochromat 60x/1.4 oil-immersion objective. Sequential scanning laser was used to avoid cross talk between different fluorochromes. Only pyramidal neurons with clear dendrites were acquired, with a $\mathrm{z}$-stack thickness of $200 \mathrm{~nm}$ (12 stacks). At least 21 neurons from three independent experiments were measured for colocalization analysis. Regions of interest (ROI) had a $10 \mu \mathrm{m} \times 5 \mu \mathrm{m} \times 2.4 \mu \mathrm{m}$ size located in the proximal (10 $\mu \mathrm{m}$ far from soma) and distal (at least $60 \mu \mathrm{m}$ far from soma) compartments of apical dendrites. After ROI selection images were cropped, then background was automatically subtracted using Imaris software (Bitplane). Images were then deconvolved using Huygens software with classical CMLE algorithm. "Coloc" function of Imaris was used to perform colocalization analysis Automatic threshold was applied to each image before Manders coefficients calculation. Images of colocalization between mRNA and RBPs are Z-stack maximum projection of representative dendrite shafts analyzed. The images were post-processed to linearly increase brightness equally in the whole panel for visualization purpose.

\section{Quantitative Imaging Analysis and Statistics of Non-radioactive In situ Hybridization}

Non-radioactive ISH was analyzed by viewing stained cultures under bright-field illumination as previously described (Tongiorgi et al., 1997; Chiaruttini et al., 2009) with slight modifications. In detail, individual preparations were coded and analyzed in a blind manner with respect to treatments. Bona-fide pyramidal neurons were randomly sampled from each culture and acquired by a Nikon AXM1200 digital camera on a Nikon E800 Microscope with interference contrast-equipped lens (60x magnification) and then analyzed with the image analysis program Image $1.44(\mathrm{NIH})$ using the "Straighten" plugin. Dendritic targeting of $B D N F$ transcripts in apical dendrites of pyramidal neurons was evaluated as the maximum distance of dendritic labeling (MDDL) measured in $\mu \mathrm{m}$ from the soma using the "Trace" function of the software Image-ProPlus 4.0 (Media Cybernetics). Straightened dendrites were "traced" in a conservative manner, starting from the base of dendrite after soma and up to the point in which in situ labeling was clearly distinguishable. At least 150 neurons from four independent experiments were measured for each condition. For both MDDL analysis and semi-quantitative densitometric analysis of BDNF mRNA ISH levels, we used standardized development time of alkaline phosphatase reaction of $40 \mathrm{~min}$ at RT. Labeling intensity was measured as a scale of gray levels from $0=$ no staining to $255=$ saturated black staining, using the software Image-ProPlus 4.0 (Media Cybernetics) as previously described (Chiaruttini et al., 2009). Background level for each dendrite was determined by evaluation of the mean gray value in the distal portion of apical dendrites of transfected neurons in which in situ labeling was not present. Background staining was then substracted from each dendrites before averaging. This procedure produces densitometric data that are expressed in arbitrary units (or gray levels). This densitometric method to quantify ISH does not require signal normalization, as previously validated in ours and other laboratories (An et al., 2008; Chiaruttini et al., 2009). Statistical significance among groups was evaluated performing Kruskal-Wallis one-way ANOVA on ranks, followed by a multiple comparison procedure with Dunn's method. 


\section{RESULTS}

\section{Inducible Dendritic Targeting of Endogenous BDNF mRNA}

We previously showed that neuronal depolarization and BDNF induce dendritic localization of BDNF mRNA in vitro (Tongiorgi et al., 1997; Righi et al., 2000), however, it remained undetermined if other neurotrophins can also induce BDNF mRNA localization in dendrites. To investigate the effect of neurotrophins we treated primary rat hippocampal neurons at 6 days in vitro (DIV) for $3 \mathrm{~h}$ with NGF, BDNF, NT-3, NT-4 (50 ng/ml) or $10 \mathrm{mM}$ $\mathrm{KCl}$. Endogenous BDNF mRNA was detected in isolated cultured cells using non-radioactive ISH using a probe targeting the CDS and hence recognizing all the possible $B D N F$ transcripts expressed (Figure 1A). Dendritic targeting of $B D N F$ transcripts was evaluated as the MDDL from the soma, normalized to untreated condition. At least 150 neurons from four independent experiments were measured for each condition. $\mathrm{KCl}$ treatment induced a $2.83 \pm 0.17$ fold increase of BDNF mRNA targeting with respect to basal culturing conditions (Figures 1B,C). Stimulation with BDNF and NT-3 induced also a significant fold increase compared to untreated cells $(1.59 \pm 0.11$ and $1.49 \pm 0.10$, respectively), while NGF and NT-4 did not significantly alter $B D N F$ mRNA distribution along dendrites (Figures 1B,C). Activity of neurotrophins and $\mathrm{KCl}$ solution used in these experiments was demonstrated by translocation of $c$-fos in the nuclei (Supplementary Figure S1). Blocking Trk receptors activity with the inhibitor K252a prevented BDNF mRNA dendritic translocation after application of BDNF or NT-3 (Figure 1C). Inhibition of Trk signaling by K252a also depressed $\mathrm{KCl}$-dependent dendritic targeting, suggesting the contribution of neurotrophin signaling during $\mathrm{KCl}$-induced neuronal depolarization, as previously described for BDNF stimulation (Righi et al., 2000). These data provide strong evidence that distal dendritic localization of endogenous $B D N F$ mRNA can be induced in hippocampal neurons by depolarization, BDNF and NT-3.

\section{Long and Short BDNF $3^{\prime}$ UTRs Respond Differently to NT-3 and BDNF}

We previously showed that upon treatment with high $\mathrm{KCl}$, the short $3^{\prime}$ UTR BDNF can target the mRNA of a reporter gene to the distal dendrites of cultured neurons (Baj et al., 2011). To investigate the role of short and long $3^{\prime}$ UTRs with respect to the stimulation with activity, BDNF or NT-3, primary rat hippocampal neurons were transfected with GFP-3' UTR short or GFP-3' UTR long chimeras. Cultures were stimulated for $3 \mathrm{~h}$ with $10 \mathrm{mM} \mathrm{KCl}$ or $50 \mathrm{ng} / \mathrm{ml}$ of each neurotrophin, and neurons were subjected to nonradioactive ISH using a DIG-labeled GFP antisense probe and finally, the MDDL from the soma was measured (Figure 2). No unspecific staining was detected using GFP sense strand probes (Figure 2D, middle panel). In resting neurons, the short $3^{\prime}$ UTR was mainly confined in the proximal dendritic

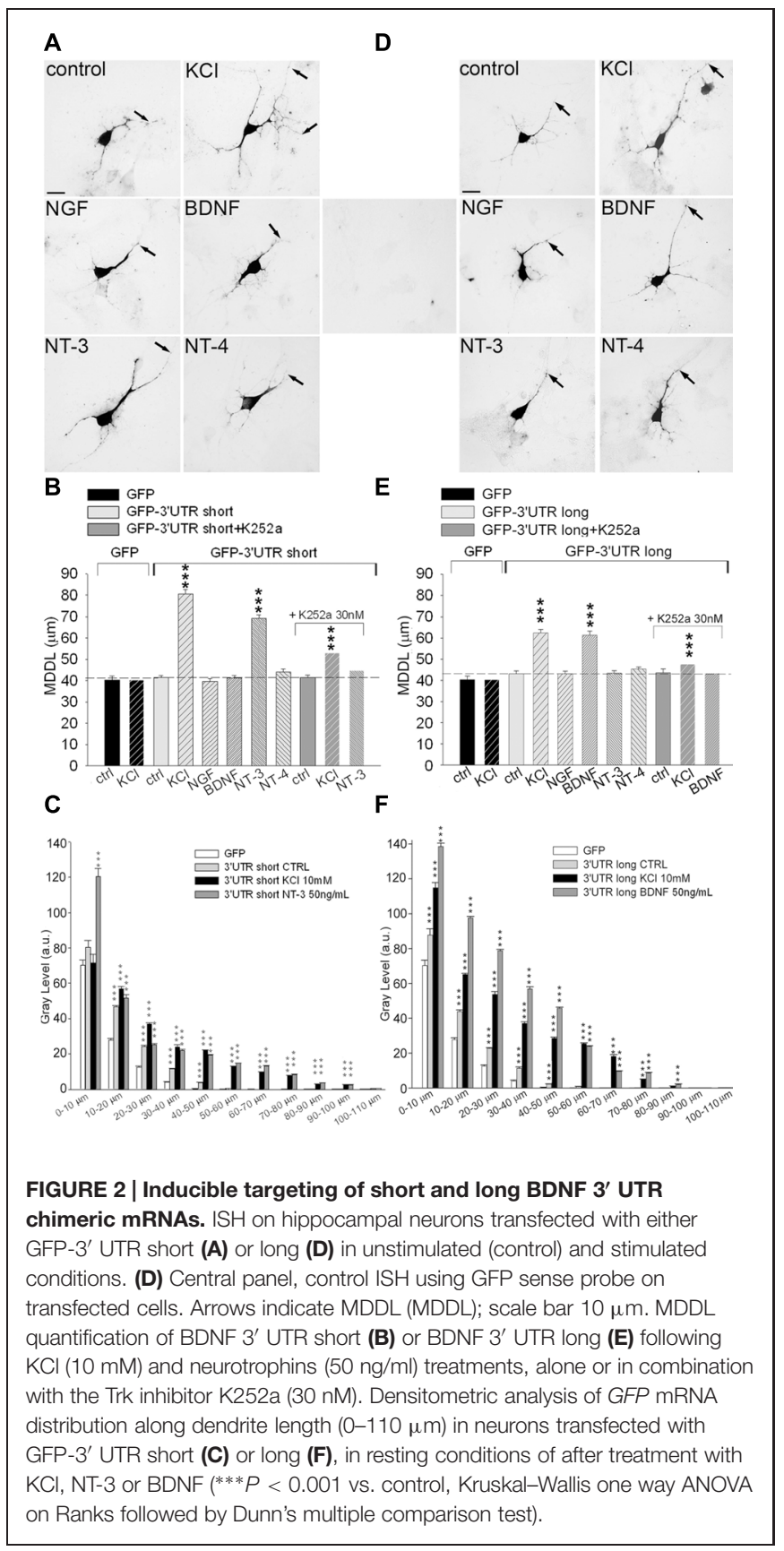

compartment $(\mathrm{MDDL}=41.56 \pm 0.82 \mu \mathrm{m})$ similar to GFP mRNA (MDDL $=40.34 \pm 1.72 \mu \mathrm{m}$; Figures 2A,B). GFP mRNA localization was not modified by neuronal depolarization $(\mathrm{MDDL}=40.36 \pm 1.87 \mu \mathrm{m})$, whilst GFP$3^{\prime}$ UTR short mRNAs showed a significant translocation in distal dendrites both after high potassium depolarization $(\mathrm{MDDL}=80.57 \pm 1.94 \mu \mathrm{m}, P<0.001)$ or treatment with NT$3(\mathrm{MDDL}=69.14 \pm 1.61 \mu \mathrm{m}, P<0.001)$. NGF, BDNF or NT-4 had no effect on GFP-3' UTR short mRNA localization (Figures 2A,B). Trk tyrosine kinase inhibitor K252a abolished the GFP-3' UTR short dendritic localization in response to NT3 application, in accordance with the results previously seen 
for endogenous BDNF mRNA (Figure 2B). Similarly, $\mathrm{KCl}$ induced translocation was significantly impaired, suggesting that a NT3-dependent mechanism plays a substantial role in activity-induced dendritic targeting of short $3^{\prime}$ UTR transcripts (Figure 2B)

Localization of the GFP-3' UTR long chimera did not differ significantly from the GFP reporter alone in unstimulated cultures $(\mathrm{MDDL}=43.14 \pm 1.36 \mu \mathrm{m})$. However, depolarization induced strong accumulation of this mRNA in distal dendrites $(\mathrm{MDDL}=62.44 \pm 1.44 \mu \mathrm{m}, P<0.001)$, similarly to the short 3' UTR constructs (Figures 2D,E). Furthermore, application of $50 \mathrm{ng} / \mathrm{ml}$ BDNF (but not NT-3, NT-4 nor NGF) induced dendritic translocation of the GFP-3' UTR long at distances comparable those induced by $\mathrm{KCl}$ depolarization $(\mathrm{MDDL}=61.38 \pm 1.92 \mu \mathrm{m}) . \mathrm{K} 252 \mathrm{a}$ application abolished BDNF-induced, and significantly reduced $\mathrm{KCl}$-dependent, 3' UTR long mRNA distal targeting, suggesting that BDNF signaling is required to enhance the depolarization effect on mRNA localization (Figure 2E). The ISH signals from the very same neurons were quantified by densitometric analysis throughout the entire dendritic length, leading to results comparable to those obtained with MDDL measurements (Figures 2C,F). Taken together, these results provide clear evidence that both the long and short $3^{\prime}$ UTR sequences are involved in inducible dendritic localization of BDNF mRNA. Dendritic targeting of $B D N F$ mRNA is modulated by neuronal depolarization $(\mathrm{KCl})$ for both regions but is specifically regulated by NT-3 for the short $3^{\prime}$ UTR and by BDNF for the long $3^{\prime}$ UTR.

\section{Activity-dependent Dendritic Targeting of BDNF Short 3' UTR mRNA In vivo}

A previous study suggested that BDNF transcripts of BDNF ${ }^{\text {lox } / \text { lox }}$ mice, lacking a functional long $3^{\prime}$ UTR, are confined in the soma in vivo (An et al., 2008). However, activity-dependent targeting in vivo of short $3^{\prime}$ UTR transcript was not evaluated. To determine whether the short $3^{\prime}$ UTR form is targeted to dendrites also in vivo, we took advantage of the same BDNF ${ }^{\text {lox}} /$ lox mouse model (Gorski et al., 2003). In WT mice in resting conditions, BDNF mRNA was detected in the soma and in the proximal dendrites of CA1 and CA3 neurons while in $\mathrm{BDNF}^{\mathrm{lox} / \mathrm{lox}}$ mice it was detectable only in the soma, as previously described (An et al., 2008; Figure 3A). However, after treatment with the pro-epileptic drug pilocarpine for $3 \mathrm{~h}$, localization of $B D N F$ transcripts in dendrites was observed both in WT and $\mathrm{BDNF}^{\text {lox/lox }}$ hippocampi, confirming the finding that BDNF mRNA splice variants with a short $3^{\prime}$ UTR can be transported in dendrites after stimulation (Figure 3A). Interestingly, in $\mathrm{BDNF}^{\text {lox/lox }}$ neurons a punctate distribution of BDNF mRNA was observed, whilst a more uniform signal was seen in WT animals. These differences may be due to the fact that the long $3^{\prime}$ UTR is lacking from distal compartments of BDNF ${ }^{\text {lox} / l o x}$ neurons and therefore staining for $B D N F$ mRNA is generally weaker. $B D F^{l o x} /$ lox mice display decreased $B D N F$ protein dendritic levels despite the total amount of protein is comparable (An et al., 2008). To test if pilocarpine treatment is able to increase $\mathrm{BDNF}$ protein levels in $\mathrm{BDNF}^{\mathrm{lox} / \mathrm{lox}}$ mice, brain sections from

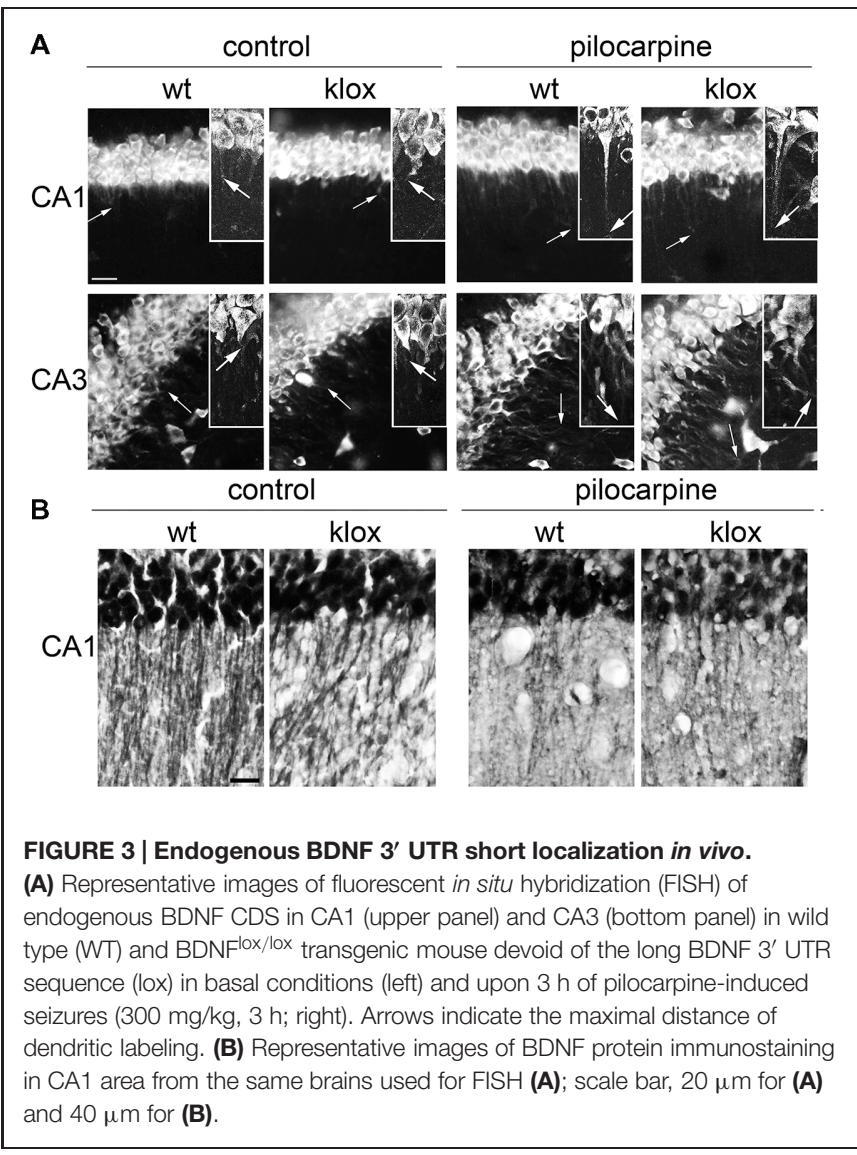

WT and mutated animals were immunostained with an antiBDNF antibody. Hippocampal neurons of pilocarpine-treated $\mathrm{WT}$ and $\mathrm{BDNF}^{\mathrm{lox} / \mathrm{lox}}$ mice were found to display comparable labeling in distal dendrites (Figure 3B), providing further evidence that BDNF can reach distal dendrites even if it is translated from transcripts expressing the $3^{\prime}$ UTR short only.

\section{Multiple RNA Binding Proteins are Associated to BDNF mRNA}

Previous evidence showed that BDNF mRNA trafficking and stabilization requires interaction with RBPs (Chiaruttini et al., 2009; Oe and Yoneda, 2010; Louhivuori et al., 2011). To identify the RBPs interacting with the $3^{\prime}$ UTR short or long, we used an in silico approach to detect evolutionary conserved regions and putative binding proteins sites on each $3^{\prime}$ UTR variant. BDNF sequences were compared among primates, mammals, and vertebrates (see Supplementary Figure S2) using phast Cons alignment software (Siepel et al., 2005). Several regions were found to be highly conserved (Figure 4A), with the short $3^{\prime}$ UTR region being the most conserved one, followed by the mid and terminal regions of the long $3^{\prime}$ UTR. To recognize binding motifs for RBPs, the bioinformatic analysis was focused on regions highly conserved among vertebrate species, which are more likely to share an evolutionary conserved biological function. We searched for consensus recognition sequences for some RBP families including cytoplasmatic polyadenylation 


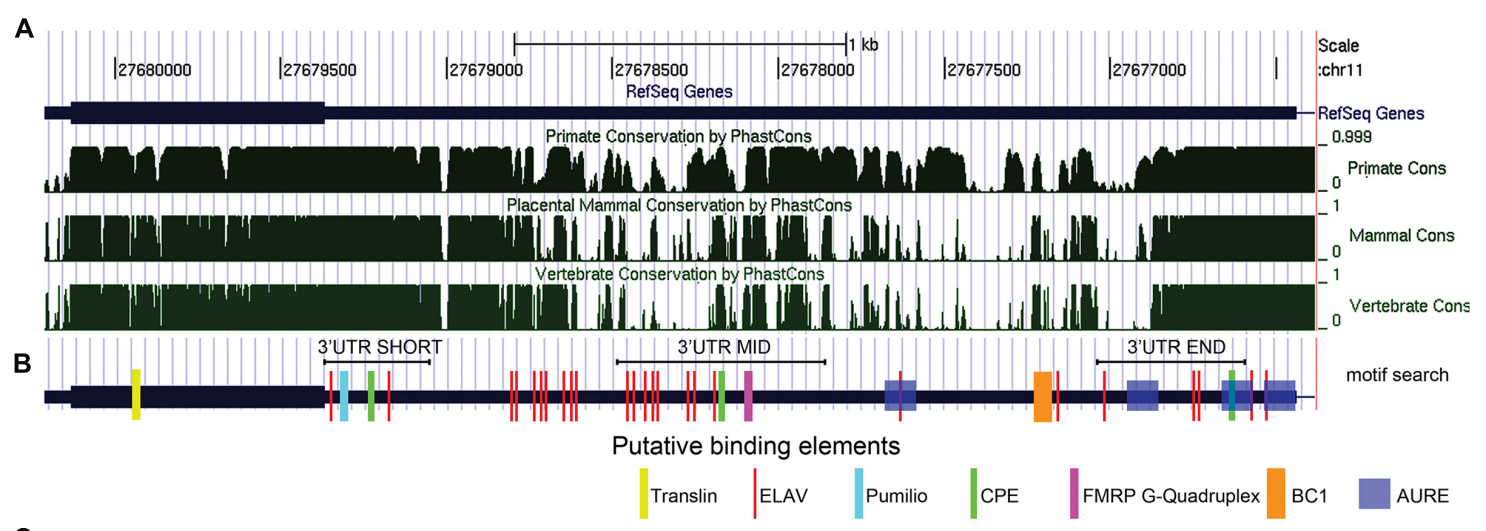

C
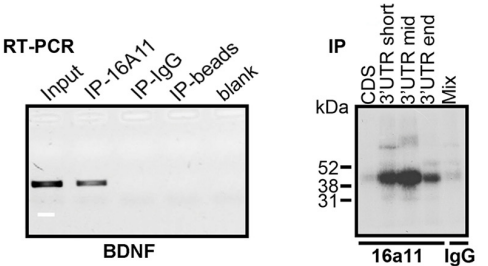

E

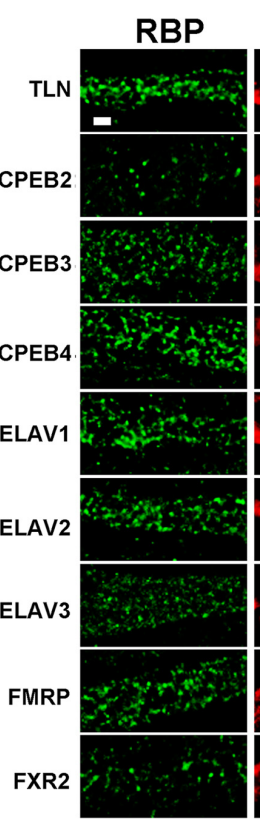

D

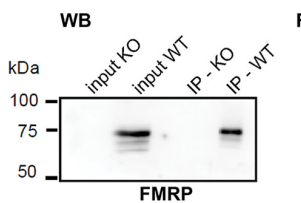

RT-PCR

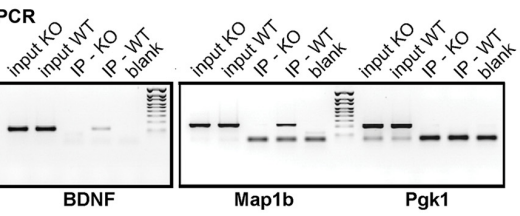

$\mathbf{F}$

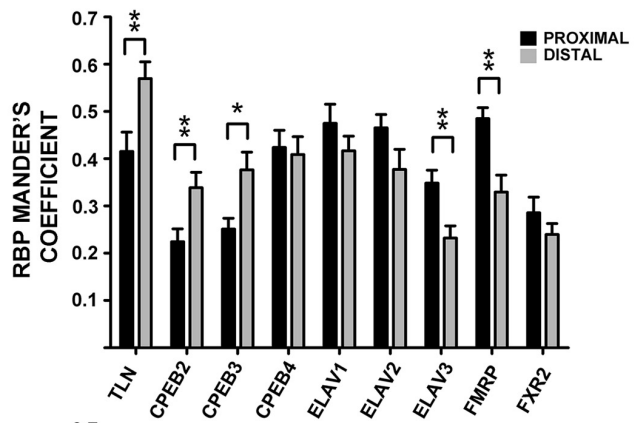

G

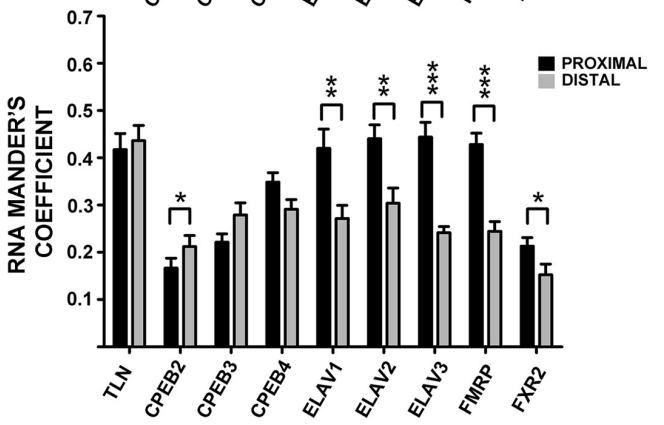

FIGURE 4 | Brain-derived neurotrophic factor mRNA interaction with RNA binding proteins (RBPs). (A) Graphical view of homology of BDNF coding regions and $3^{\prime}$ UTR among Primates, Mammals, and vertebrates. Similarity scores range from 0 (=no homology) to 1 (identical sequence). Numbers indicate the nucleotide position of BDNF gene on chromosome 11. (B) Putative binding sites for RBPs indicated with different colors at the corresponding positions along BDNF mRNA. Positions of the short 3' UTR, long-mid 3' UTR and long-end sequences used in UV-CLIP assays in (C) are also shown. (C, left panel) Reverse transcriptase-PCR of BDNF mRNA immunoprecipitated with an antibody against the neuronal ELAV proteins (IP-16A11), or a control lgG antibody (IP-lgG) or no antibody (IP-beads). Total brain RNA (Input) and no sample (Blank) were used as a positive and a negative control, respectively; (right panel) UV-CLIP assay with an anti-neuronal ELAV proteins antibody (IP-16a11) to immunoprecipitate RNA-protein complexes formed in presence of murine brain protein lysate and radiolabeled BDNF CDS, 3' UTR short, or 3' UTR long-mid and 3' UTR long-end ribobrobes. As a negative control, UV-CLIP was performed using an anti-lgG antibody with a mix of all the BDNF riboprobes used. (D) Immunoblot assay to test specificity of the anti-FMRP antibody in inputs and immunoprecipitates from WT and Fmr1 knockout (KO) mice (left panel). Reverse transcriptase-PCR of BDNF mRNA recovered from immunoprecipitates from WT and Fmr1 knockout lysates upon CLIP assay (middle panel). Map1b, a known mRNA target of FMRP protein, was used as a positive control, while Pgk1, an unrelated mRNA, as a negative control. Blank, no sample in Reverse transcriptase-PCR reaction. (E) Colocalization analysis of endogenous BDNF mRNA with different RBPs. Immunofluorescence signal from the different RBPs (green) and from endogenous BDNF mRNA (red) in proximal dendrites are shown separately (RBP, mRNA) and merged (MERGE). Images are Z-stack maximum projection of 12 stacks confocal images. Scale bar: $1 \mu \mathrm{m}$. (F,G) Graphs report the Manders coefficient (Y-axis) of RBPs signal colocalized with endogenous BDNF mRNA (F) and BDNF mRNA signal colocalized with the different RBP (G) in proximal (dark gray) and distal (light gray) dendrites. Data are reported as mean \pm SEM. Statistical significance of proximal vs. distal Manders coefficients of colocalization was evaluated performing $t$-test if the normality test was passed, or Mann-Whitney Rank-Sum test $\left({ }^{*} P<0.05 ;{ }^{*} P<0.01{ }^{* * *} P<0.001\right)$. 
element binding proteins (CPEBs), embryonic lethal abnormal vision like proteins (ELAVs) and Fragile $\mathrm{X}$ mental retardation protein (FMRP), which are known to bind to short, well-defined RNA sequences and are involved in RNA transport, translation, and stabilization. The short $3^{\prime}$ UTR (nts 1-321) displays one CPEB binding site and two different conserved sites for ELAV proteins (the upper $5^{\prime}$ site is referred here as to "ELAV up" and the $3^{\prime}$ most as "ELAV down"; Figure 4B). Additionally, in this region we found two other conserved sites, a Nanos response element (NRE) and a CUG rich region representing a potential target for Pumilio, a translational regulator (Wickens et al., 2002), and for the CUG-binding protein (CUGBP), known to regulate splicing, deadenylation, mRNA stability and translation (Philips et al., 1998; Timchenko et al., 1999; Ladd et al., 2001; Savkur et al., 2001; Paillard et al., 2003; Moraes et al., 2006; Mori et al., 2008). Despite the high conservation degree of these sequences, we did not consider Pumilio and CUGBPs in the present study, since so far there are no clear reports assessing their involvement in regulation of mRNA transport. Even if the BDNF long 3' UTR showed a higher degree of variability among species when compared to the short $3^{\prime}$ UTR, three conserved "hot spots" were identified (Figures 4A,B). The first conserved region, located at the boundary with the $3^{\prime}$ UTR short, presents an "ELAV rich region" with a cluster of binding sites for the ELAV-1 family member (HuR, red bars in Figure 4B). A nearby second conserved sequence, in the center of the long $3^{\prime}$ UTR, is characterized by a G-quartet like structure, known to be recognized by FMRP (Darnell et al., 2001). Finally, a third region located at the end of the long $3^{\prime}$ UTR shows a pattern of ciselements similar to the one found in the short $3^{\prime}$ UTR, with CPEs and ELAV recognition sites. Additionally, we found one BC1 (Rozhdestvensky et al., 2001) and several AU-rich response element (AURE), especially in the $3^{\prime}$ terminal region of the long $3^{\prime}$ UTR, which support a previously suggested possible involvement of hnRNPA2 RBP (Raju et al., 2011).

In order to detect an interaction of ELAVs with BDNF transcripts, we performed a RNA immunoprecipitation (RIP) assay on mouse brain lysates using a pan-neuronal ELAV (nELAV) antibody, followed by Reverse transcriptase-PCR. This analysis showed that BDNF mRNA was selectively recovered from anti-nELAV immunoprecipitates (IPs), but not from control-IgG IPs or in presence of beads alone (Figure 4C, left panel). To test the specificity of binding of nELAVs to the BDNF 3' UTR sequence, we used radiolabeled riboprobes corresponding to BDNF short $3^{\prime}$ UTR and CDS in UV CrossLinking Immunoprecipitation (UV-CLIP) assays with mouse brain protein lysates. In addition, we used two riboprobes corresponding to the central (mid, nts 890-1510) or terminal (end, nts 2339-2790) regions of the $3^{\prime}$ UTR long sequence that also contained ELAV consensus binding motifs (Figures 4B,C, right panel). No RNA-protein complex formed in presence of the CDS-specific riboprobe, whilst specific nELAV-BDNF RNA complexes were recovered in presence the short, mid and end 3' UTR riboprobes (Figure 4C, right panel). To test for FMRP binding, we performed similar CLIP experiments with mouse brain lysates using a previously described polyclonal rabbit anti-FMRP antibody (Davidovic et al., 2011). The specificity of the anti-FMRP antibody used was first proven by immunoprecipitation assays using WT and FMR1 knockout mouse brains as a negative control (Figure 4D, left). Accordingly, endogenous BDNF mRNA could be amplified via Reverse transcriptase-PCR from WT but not FMR1 knockout mouse brains immunoprecipitates (Figure 4D, middle panel). Map1b and $P g k 1$ mRNAs were used as positive and negative controls for FMRP binding, respectively (Figure 4D, right panel). Previous studies already demonstrated that CPEBs physically bind to BDNF CDS and 3' UTR mRNA (Oe and Yoneda, 2010) and therefore the binding experiments for these proteins were not performed.

To verify if the above mentioned RBP are colocalized with BDNF mRNA in dendrites, we performed double labeling experiments with FISH against endogenous BDNF transcripts coupled to immunofluorescence (IF) for RBPs family members in unstimulated cultures (Figure 4E). Tyramide Amplification System was employed to visualize endogenous BDNF mRNA in distal dendrites, due to its intrinsic low abundance in such compartment of resting cultured neurons (Baj et al., 2013; Will et al., 2013). The different RBPs taken in account in this study showed a similar distribution in dendrites, suggesting that they represent shared components of dendritic mRNA transporting granules. In proximal dendrites (Figures 4E-G), in unstimulated cultures, almost half of the staining spots of Translin, CPEB4, ELAV1, ELAV2, and FMRP were colocalized with endogenous BDNF mRNA (Manders coefficient 0.415 $\pm 0.041,0,424 \pm 0.036$, $0.475 \pm 0.040,0.465 \pm 0.028$, and $0.485 \pm 0.023$, respectively), while other transporting granules were less colocalized, with Manders coefficient values ranging from 0.224 to 0.348 . Similarly BDNF mRNA signal results to be more colocalized in the proximal compartment with Translin, ELAV1, ELAV2, ELAV3, and FMRP granules (Manders coefficient 0.417 \pm 0.034 , $0,420 \pm 0.041,0.440 \pm 0.029,0.444 \pm 0.031$, and $0.423 \pm 0.024$ respectively). In distal compartments more than half of the transporting granules stained for Translin were colocalized with BDNF mRNA (Manders coefficient $0.579 \pm 0.035$ ), while other RBPs display similar colocalization degree with RNA, except for the less colocalized ELAV3 and FXR2 (Manders coefficient $0.232 \pm 0.026$ and $0.240 \pm 0.023$, respectively). Moreover, BDNF mRNA displayed the highest colocalization rate with Translin protein (Manders coefficient $0.436 \pm 0.032$ ) confirming its involvement in this mRNA trafficking as previously demonstrated (Chiaruttini et al., 2009) while it showed a heterogeneous colocalization with other RBPs (Manders coefficient ranging from 0.152 to 0.304 ). CPEB-1 and ELAV-4 were undetectable after FISH, therefore they have been omitted in the colocalization analysis. Statistical comparison revealed that RBPs colocalization with BDNF mRNA was significantly higher in distal dendrites than in proximal dendrites for translin, CPEB2, CPEB3, while it was higher in proximal than in distal for ELAV3 and FMRP, and was equally distributed for CPEB4, ELAV1 and 2, and FXR2 (Figure 4F). Viceversa, when colocalization was analyzed taking BDNF mRNA as reference, we found that BDNF mRNA was significantly more localized with ELAV1, 2, 3, FMRP and FXR2 in proximal dendrites than in distal (Figure 4G), suggesting that this mRNA 
and these RBPs interact more in the initial segment of the dendrites.

\section{Different Set of RBPs Regulates Long and Short 3' UTRs Dendritic Targeting}

To test if the identified RBPs contribute to the inducible mechanism of BDNF mRNA targeting to dendrites, dendritic localization of GFP-BDNF 3' UTRs was measured following $\mathrm{KCl}$, NT-3 or BDNF stimulation in neurons co-transfected with siRNA cocktails against each member of the CPEB, ELAV, or FRXP families. Analysis of siRNA efficacy showed a high degree of silencing of target RBPs (Figures 5A,D and 6F; Supplementary Table S4). The specificity of siRNAs used and the lack of off-target effects among homologous members of the CPEB and ELAV families were confirmed by Reverse transcriptase-PCR (Figures 5A,D; Supplementary Table S4). When considering the short BDNF 3' UTR, both activity-dependent and NT3 mediated localization of the reporter was found to require CPEB-1 and CPEB-2, but not CPEB-3 or CPEB-4 (CPEB-1 siRNA $\mathrm{KCl} \mathrm{MDDL}=37.16 \pm 1.12 \mu \mathrm{m}, \mathrm{CPEB}-2$ siRNA $\mathrm{KCl}$ $\mathrm{MDDL}=37.48 \pm 1.63 \mu \mathrm{m},{ }^{* * * *} P<0.001$ respect to $\mathrm{KCl}$ no siRNA; CPEB-1 siRNA NT-3MDDL $=37.69 \pm 1.09 \mu \mathrm{m}$, CPEB-2 siRNA NT-3 MDDL $=38.96 \pm 1.18 \mu \mathrm{m},{ }^{\# \# \#} P<0.001$ respect to NT-3 with no siRNA). A control siRNA against luciferase had no effect on BDNF mRNA targeting (Figure 5B, scramble). Disruption of the CPE binding site through site

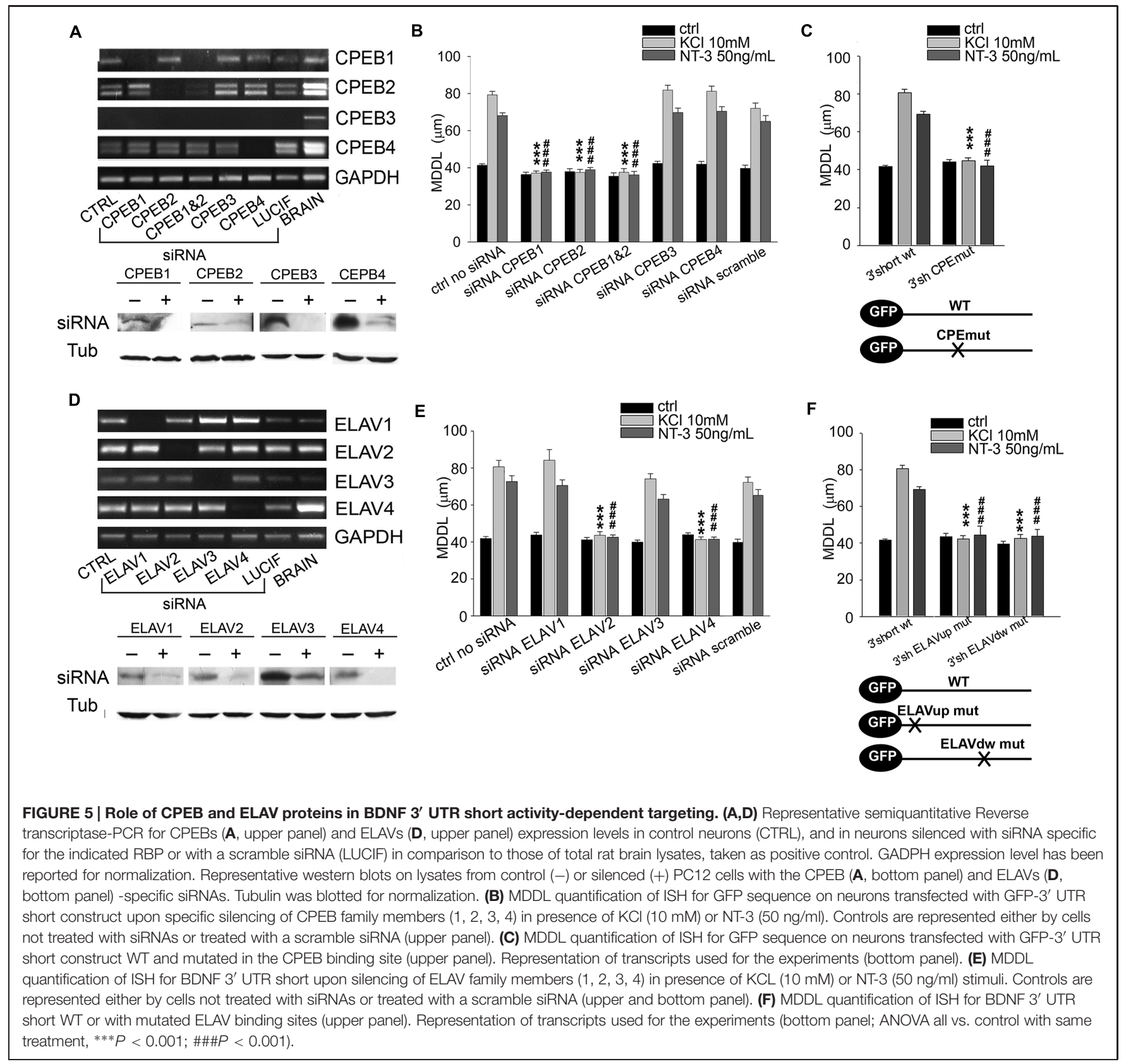



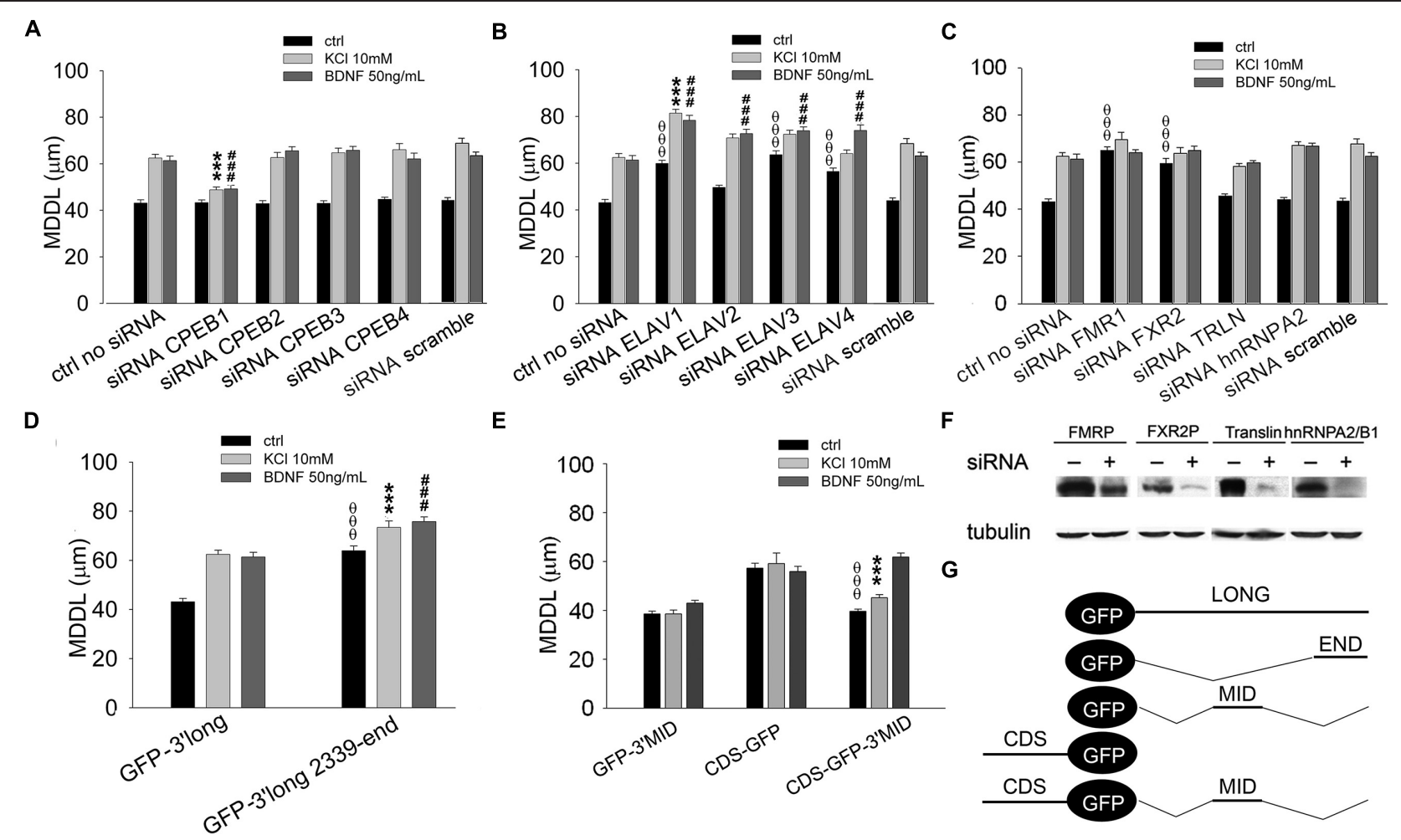

E
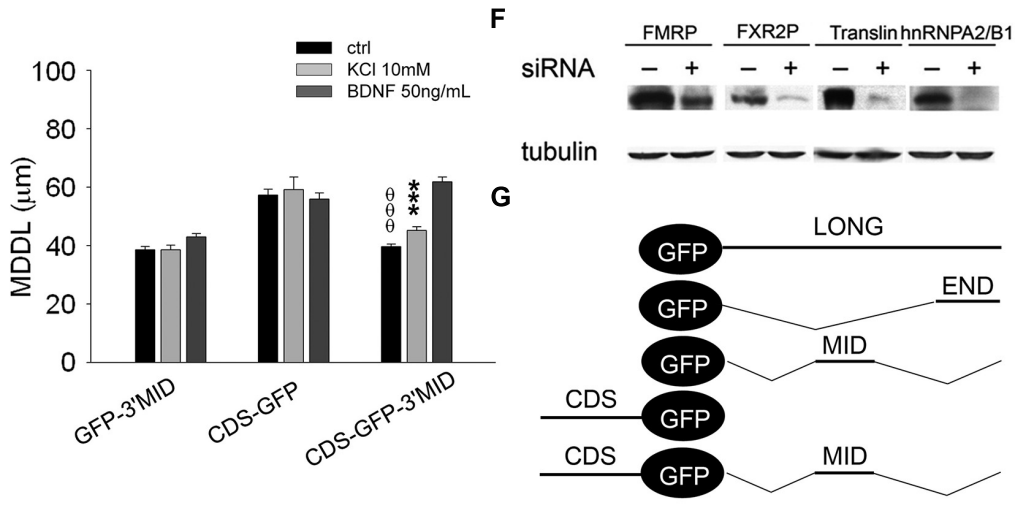

FIGURE 6 | Role of CPEBs, ELAVs, and FMRP proteins in BDNF $\mathbf{3}^{\prime}$ UTR long activity-dependent targeting. (A-C) MDDL quantification of ISH for GFP sequence on neurons transfected with GFP-3' UTR long construct upon silencing of different RBPs (CPEB-1-4, A; ELAV-1-4, B; FMR1, FXR2, TRLN, hnRNPA2, C) in resting conditions or after $\mathrm{KCl}(10 \mathrm{mM})$ or BDNF $(50 \mathrm{ng} / \mathrm{ml})$ treatment. Controls are represented either by cells not treated with siRNAs or treated with a scramble siRNA (upper panel). (D) MDDL quantification of ISH for GFP sequence on neurons transfected with GFP-3' UTR long construct containing full-length or final portion (nt 2339-end) of BDNF 3' UTR long in resting conditions or after $\mathrm{KCl}$ (10 mM) or BDNF (50 ng/ml) treatment. (E) MDDL quantification of ISH for GFP sequence on neurons transfected with BDNF CDS-GFP and BDNF CDS-3' UTR MID-GFP constructs, in resting conditions and after KCl (10 mM) or BDNF (50 ng/ml) treatment (left panel). Graphical representation of the constructs used for the experiments is reported in the bottom right panel (ANOVA all vs. control with same treatment, ${ }^{\theta \theta \theta} P<0.001$; ${ }^{* * *} P<0.001$; \#\#\#P <0.001). (F) Representative western blots on lysates from control $(-)$ or silenced (+) PC12 cells with FMRP, FXR2, Translin, hnRNPA2/B1 specific siRNAs. Tubulin was blotted for normalization. (G) Schematic representation of GFP chimaeric transcripts.

directed mutagenesis (UUUUAU to CGAUCG, Figure 5C) completely suppressed mRNA sorting in dendrites in response to extracellular stimuli, and further confirmed the role of CPEBs in BDNF mRNA trafficking (Huang et al., 2006). However, it is unclear whether CPEB 2 can bind directly to the mRNA, since UUUUAU is the consensus sequence for CPEB-1, and a specific CPEB-2 recognition site has not been described yet (Huang et al., 2006). Both ELAV-2 and ELAV-4 were required for $\mathrm{KCl}$ and NT-3-dependent transport of the $3^{\prime}$ UTR short (ELAV-2 siRNA KCl MDDL $=43.57 \pm 1.99 \mu \mathrm{m}$, ELAV-4 siRNA NT-3 $\mathrm{MDDL}=41.32 \pm 1.39 \mu \mathrm{m},{ }^{* * *} P<0.001$ respect to no siRNA $\mathrm{KCl}$; ELAV-2 siRNA NT-3 MDDL $=42.53 \pm 1.28 \mu \mathrm{m}$, ELAV-4 siRNA NT-3 MDDL $=41.48 \pm 1.14 \mu \mathrm{m},{ }^{* * *} P<0.001$ respect to no siRNANT-3; Figures 5E,F). The other two family members, ELAV-1 and -3, did not result involved in dendritic localization of BDNF 3' UTR short. Involvement of ELAV-2 and-4 RBPs was further confirmed by the fact that disruption of either the $5^{\prime}$ or $3^{\prime}$ ELAV binding motifs (AUUUAU to AGCGCG) blocked BDNF $3^{\prime}$ UTR short dendritic targeting upon stimuli (Figure 5F). The relative RNA levels of these mutants were compared to the parental GFP and WT GFP $3^{\prime}$ UTR short mRNAs to rule out the possibility that the lack of dendritic localization of the $3^{\prime}$ UTR mutants could be related to a decreased stability or expression and indeed we did not observe any significant difference (Supplementary Figures S3A,B). In summary, these results clearly demonstrate that $\mathrm{KCl}$ and $\mathrm{NT}-3$ are able to induce distal dendritic localization of BDNF $3^{\prime}$ UTR short through a complex post-transcriptional regulatory mechanism that requires the interaction of CPEB-1, CPEB-2, ELAV-2, and ELAV-4 RBPs.

A similar approach was used to identify key RBPs modulating the long BDNF 3' UTR localization in distal dendrites upon $\mathrm{KCl}$ or BDNF stimuli. Dendritic targeting of the long isoform required CPEB-1 but not CPEB-2, CPEB-3, or CPEB-4 in both conditions $\left(\mathrm{KCl} \mathrm{MDDL}=48.84 \pm 1.15 \mu \mathrm{m},{ }^{* * *} P<0.001\right.$ respect to no siRNA $\mathrm{KCl}, \mathrm{BDNF} \mathrm{MDDL}=49.17 \pm 1.55 \mu \mathrm{m},{ }^{\# \# \# P<0.001}$ respect to no siRNA BDNF; Figure 6A). Silencing of individual ELAV family members induced an unexpectedly complex pattern of responses. ELAV-1, -3 , and -4 down-regulation promoted a significant increase in $3^{\prime}$ UTR long targeting after stimulation and even at resting conditions, in particular following silencing of ELAV-1 (ctrl MDDL $=59.90 \pm 1.31 \mu \mathrm{m},{ }^{\theta \theta \theta} P<0.001$ respect to $c$ trl no siRNA; $\mathrm{KCl} \mathrm{MDDL}=81.40 \pm 1.64 \mu \mathrm{m},{ }^{* * *} P<0.001$ 
respect to no siRNA $\mathrm{KCl} ; \mathrm{BDNF} \mathrm{MDDL}=78.36 \pm 2.13 \mu \mathrm{m}$, ${ }^{\# \# \#} P<0.001$ respect to no siRNA BDNF; Figure 6B). A similar increase in dendritic targeting of the $3^{\prime}$ UTR long was found at resting conditions also with siRNAs against the Fragile-X proteins (FXRPs) FMRP1 and FXR2, consistent with our recent study on total BDNF mRNA localization in $\mathrm{Fmrl}^{-/-}$mice (Louhivuori et al., 2011; ${ }^{\theta \theta} P<0.001$, Figure 6C). Interestingly, activity- or neurotrophin-induced dendritic targeting was normal in absence of FMRP or FXR2 (Figure 6C). Additionally, the role of other two RBPs, Translin and hnRNPA2/B1 was tested. Translin was used as an internal control since this protein does not appear to be involved in the sorting of $3^{\prime}$ UTR long while hnRNPA2/B was tested since putative AURE recognition elements have been identified in the terminal part of the $3^{\prime}$ UTR long. No significant alterations of BDNF $3^{\prime}$ UTR long mRNA targeting were observed after Translin or hnRNPA2/B1 silencing (Figure 6C). These findings suggest that a specific set of RBPs is able to retain $3^{\prime}$ UTR long-containing splice variants in the proximal dendritic compartment of resting neurons while other RBPs are involved in the dendritic targeting. These "soma-restrictive" proteins display clustered recognition sites in the $3^{\prime}$ UTR long central region which is remarkably well-conserved throughout the evolution (nts 890-1510, Figure 4B) while RBPs involved in the dendritic targeting appeared located mostly at the $3^{\prime}$ end of long $3^{\prime}$ UTR region (nts 2339-2790, Figure 4B).

\section{The Long 3' UTR Contains Two Distinct RNA Localization Signals with Opposing Functions}

We speculated that the central region of the $3^{\prime}$ UTR long might contain a retention signal, able to counteract both the constitutive dendritic targeting signal in the coding region of BDNF mRNA (Chiaruttini et al., 2009) and the inducible signal present in the terminal part of the $3^{\prime}$ UTR long. To test this hypothesis, the terminal $3^{\prime}$ UTR long sequence (nts 2339-2790) was inserted at the $3^{\prime}$ of the GFP reporter (GFP-3' UTR END, Figure 6G). This chimera displayed an increased distal targeting with respect to the full length $3^{\prime}$ UTR long under basal conditions $\left(\mathrm{MDDL}=63.96 \pm 1.93 \mu \mathrm{m},{ }^{\mathrm{OOO}_{P}}<0.001\right.$ respect to ctrl $3^{\prime}$ UTR long), comparable to that observed when ELAV-1, 3 , or -4 were silenced (compare Figures $6 \mathrm{D}$ and $6 \mathrm{~B}$ ). At the same time, both $\mathrm{KCl}$ and $\mathrm{BDNF}$ induced a small but significant increase in distal transport of the terminal $3^{\prime}$ UTR long sequence with respect to the full-length $3^{\prime}$ UTR long (3' UTR END $\mathrm{KCl}$ $\mathrm{MDDL}=73.41 \pm 2.61 \mu \mathrm{m},{ }^{* * *} P<0.001$ respect to $\mathrm{KCl} 3^{\prime}$ UTR long; 3' UTR END BDNF MDDL $=75.79 \pm 1.88 \mu \mathrm{m}$,

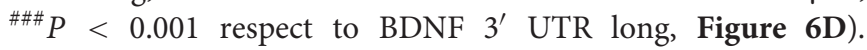
To test the role of the central region of the $3^{\prime}$ UTR long, the sequence 849-1533 nt was cloned downstream the GFP reporter (GFP-3' UTR MID, Figure 6G). The 3' UTR MID fragment did not respond to any stimulus suggesting the absence of DTE while the CDS fragment was constitutively localized in dendrites (Figure 6E). However, when the central region was inserted at the $3^{\prime}$ end of the CDS-GFP construct (CDSGFP-3'MID, Figure 6G; Chiaruttini et al., 2009), it completely suppressed the constitutive dendritic localization of the CDS
(CDS-GFP-MID ctrl MDDL $=39.65 \pm 0.91 \mu \mathrm{m}$ vs. CDS-GFP ctrl $\mathrm{MDDL}=57.25 \pm 2.0 \mu \mathrm{m},{ }^{\theta \theta \theta} P<0.001$, Figure 6E). Notably, this retention signal was relieved by BDNF (CDS-GFP-MID BDNF $\mathrm{MDDL}=61.85 \pm 1.63 \mu \mathrm{m})$, but not by stimulation with $\mathrm{KCl}$ (CDS-GFP-MID KCl MDDL $=45.17 \pm 1.28 \mu \mathrm{m},{ }^{* * *} P<0.001$ respect to $\mathrm{KCl}$ GFP-CDS, Figure $6 \mathrm{E}$ ).

\section{DISCUSSION}

This study provides evidence of dendritic transport of both short and long BDNF $3^{\prime}$ UTR variants and unravels the core molecular mechanisms underlying inducible dendritic targeting of these two BDNF mRNA forms. A remarkable outcome of this study is the strikingly selective response to NT-3 for short $3^{\prime}$ UTR and to BDNF for long $3^{\prime}$ UTR. Activity- and NT3-dependent dendritic targeting of $3^{\prime}$ UTR short requires CPEB-1,2 and ELAV-2,4 while dendritic targeting of long $3^{\prime}$ UTR relies on a more complex mechanism. This includes BDNF-dependent release of somaretention signals mediated by ELAV-1,3,4, FMRP and FXRP2, and $\mathrm{KCl} / \mathrm{BDNF}$-activation of inducible targeting signals mediated by CPEB-1.

We found that Neurotrophin-3 activates dendritic targeting of $B D N F$ short $3^{\prime}$ UTR and BDNF activates the long $3^{\prime}$ UTR form. NT-3 was previously shown to be able to redistribute mRNAs to distal dendrites in cultured neurons but the mechanism has remained unknown (Knowles and Kosik, 1997). In addition, NT-3 is known to promote beta-actin mRNA localization within axonal growth cones through a mechanisms requiring blockade of microtubule depolymerisation following activation of cAMP-dependent protein kinase A (PKA; Zhang et al., 1999). A remarkable finding of our study is that NT-3 can regulate the trafficking selected isoforms of BDNF. The reciprocal interplay between BDNF and NT-3 has been previously investigated in vitro and in vivo (Lindholm et al., 1994; McAllister et al., 1997; Patz and Wahle, 2006). BDNF and NT-3 have been shown to play counteracting effects in regulating cortical dendritic growth during development (McAllister et al., 1997). Interestingly, the receptor for NT-3, TrkC, is the earliest neurotrophin receptor expressed during brain development, followed by a later expression of TrkB (Bernd, 2008). Moreover, in visual cortex NT3 mRNA levels, detected prenatally, dramatically decrease at later stages of development, with an opposing trend for BDNF mRNA (Lein et al., 2000; Patz and Wahle, 2006). BDNF and NT-3, which act presumably by activating TrkB and TrkC receptors, coupled to activation of similar signaling mechanisms, have differential effects on dendritic targeting of BDNF mRNAs. Previous studies suggest, however, that mRNA dendritic transport activated by NT-3 or BDNF may be induced through different mechanisms which also govern protein translation at synapses (Leal et al., 2014). For instance, while it was previously shown that BDNF promotes the transport of its own mRNA along dendrites through a PI3K-dependent mechanism (Righi et al., 2000), NT-3 was shown to induce dendritic trafficking of beta-actin mRNA through a PKA-dependent mechanism (Zhang et al., 1999).

There is a general consensus that BDNF mRNA levels in distal dendritic processes are low both under resting conditions and 
after stimulation in vitro and in vivo (Tongiorgi et al., 1997, 2004; An et al., 2008; Will et al., 2013). It has been proposed that BDNF mRNA is present in low amounts in dendrites, most likely because of a short half-life compared to other dendritic mRNAs (Will et al., 2013) and it has been suggested that neuronal activity may selectively increase stability of the long $3^{\prime}$ UTR BDNF mRNA by interactions with the RBP ELAV-1/HuD (Fukuchi and Tsuda, 2010; Allen et al., 2013). However, a previous study showed that BDNF short and long $3^{\prime}$ UTR variants are equally stabilized by activity (Fukuchi and Tsuda, 2010) and interactions of ELAV-1/HuD with the short $3^{\prime}$ UTR were described (Lim and Alkon, 2012). The lack of effect of $\mathrm{KCl}$ depolarization on $B D N F$ mRNA decay in our conditions, suggests that its increase in dendrites is due to active transport rather than increased stability. Collectively, these previous studies and the results presented here, suggest that the most likely cause of the low levels of $B D N F$ mRNA observed in distal dendrites is the result of a tight activitydependent regulation of transport, which limits the quantity of $B D N F$ mRNA available in dendrites.

Neither short nor long BDNF 3' UTR mRNAs were found to require CPEB3 or CPEB4 for their dendritic localization. This is an interesting result, since both these CPEB-family members were shown to be required for synaptic plasticity and dendritic spine changes in Aplysia and mouse, through a prionlike mechanism which confers these proteins the ability to form dynamic aggregates (Fioriti et al., 2015), and which does not appear to be involved in BDNF mRNA trafficking. Another peculiar aspect of CPEB3 is that it has been recognized as self-cleaving ribozyme throughout the evolution (Salehi-Ashtiani et al., 2006), which may explain why we and others (Morgan et al., 2010) found low cellular levels of this mRNA by PCR, in front of clearly detectable protein levels by western-blot and immunofluorescence.

We provide conclusive in vitro and in vivo evidence that $B D N F$ transcripts with a short $3^{\prime}$ UTR can be targeted to dendrites in an activity-dependent manner by binding to CPEB-1, as previously suggested by two different laboratories (Oe and Yoneda, 2010; Baj et al., 2011). In addition, we show here that inducible dendritic targeting of the $3^{\prime}$ UTR short requires also ELAV-2 and -4 . Interaction between the two ELAV sites on the short $3^{\prime}$ UTR may explain why the absence of either ELAV-2 or ELAV4 leads to disruption of mRNA short targeting in dendrites. It has been suggested that ELAV-2-4 dimerization may allow the formation of RNA transporting granules able to interact with the cytoskeleton for transport and with the translational machinery (Gao and Keene, 1996; Antic and Keene, 1998). Moreover, we found one highly conserved CPEB-1 binding site also in the terminal part of long $3^{\prime} \mathrm{UTR}$, in close proximity to several motifs recognized by ELAV proteins; this region resulted to be a novel inducible DTE. Even if AU-rich binding sites were found in the long $3^{\prime}$ UTR, silencing of hnRNPA2/B1 did not affect long $3^{\prime}$ UTR mRNA trafficking most likely because of compensatory binding by hnRNP CBF-A (CArG Box binding Factor A), which was previously shown to be involved in BDNF mRNA trafficking (Raju et al., 2011). In the mid region of the long 3' UTR, we identified a previously unknown retention signal able to overcome the constitutive dendritic targeting signal in the CDS mediated by Translin. These findings are in accordance with the observed increase in BDNF mRNA in dendrites of FMR1 knockout mice under resting conditions (Louhivuori et al., 2011) which might account for an increased susceptibility to epileptic seizures in these animals (El Idrissi et al., 2005). Notably, FMR1 KO mice were found to have an exaggerated mTOR and PI3K activation (Sharma et al., 2010). Since mRNA transport in dendrites can be mediated by PI3K (Righi et al., 2000), it is conceivable that the lack of targeting repression by FMRP and the enhanced PI3K signaling may provide a synergistic effect on BDNF mRNA transport. In contrast, the dynamics of short $3^{\prime}$ UTR localization seem to rely on the activation of dormant targeting elements and proteins, apparently without a soma-retention mechanism. Interestingly, a similar organization of targeting elements has been observed in CaMKII $\alpha$ a prominent dendritically localized transcript. In fact, two opposing localization signals have been identified at the level of CaMKII $\alpha 3^{\prime}$ UTR: a DTE in the first 28-56 nts of $3^{\prime}$ UTR, promoting RNA dendritic trafficking (also known as the CNDLE sequence), that is overridden by a downstream retention signal whose inhibition is relieved after $\mathrm{KCl}$-induced depolarization (Mori et al., 2000). In CaMKII $\alpha$ mRNA, two CPE elements in CaMKII $\alpha 3^{\prime}$ UTR seem to facilitate mRNA transport and translational activation (Huang et al., 2002). In addition, it has been reported that the presence of a translin binding site at the level of the coding region, is necessary for transport of CaMKII $\alpha$ mRNA in dendrites (Severt et al., 1999), as for BDNF mRNA. In BDNF 3' UTR mRNA, we found AU-rich regions, ELAV binding sites and a G-quartet-like structure similar to CaMKII $\alpha$ (for comparison, see Dictenberg et al., 2008). Finally, CaMKII $\alpha$ mRNA might be alternatively polyadenylated to generate a short or a long $3^{\prime}$ UTR, with the latter being much more abundant than the former. This striking parallelism between BDNF and CaMKII $\alpha$ cis and trans-elements involved in their activity-dependent subcellular sorting further supports the "RNA operon theory" (Keene and Tenenbaum, 2002), by which common signals and RBPs are shared by different mRNAs with common functions (e.g., synaptic plasticity and potentiation).

The results shown here, together with previous findings from our laboratory, provide strong evidence that BDNF mRNAs display both activity-dependence and transcript selectivity. Transcript selectivity is mediated by signals located in the $5^{\prime}$ UTRs that for some variants may be either permissive to distal dendritic targeting or, in other variants, may promote mRNA retention in the soma/proximal dendrites by overriding localization signals harbored in the CDS and $3^{\prime}$ UTRs (Chiaruttini et al., 2009). These findings, together with the role of both $3^{\prime}$ UTRs in activity-dependent dendritic localization, as shown here, strongly argue in favor of a mechanism of BDNF mRNA subcellular sorting regulated by a tripartite signal $\left(5^{\prime}\right.$ UTRs $=$ selectors, CDS $=$ constitutive DTE, and $3^{\prime}$ UTRs = inducible DTE). In conclusion, we propose a model in which inducible dendritic targeting signals are harbored in both $3^{\prime}$ UTRs which respond selectively to different extracellular stimuli, thus proving the basis for a differential regulation of BDNF variants for the fine tuning of distal dendritic compartment plasticity. 


\section{ACKNOWLEDGMENT}

This work was supported by Telethon Foundation GGP08258, PRIN 2010-11 2010N8PBAA from MIUR, and FRA to ET; R01 EY14998 to KJ.

\section{REFERENCES}

Aid, T., Kazantseva, A., Piirsoo, M., Palm, K., and Timmusk, T. (2007). Mouse and rat BDNF gene structure and expression revisited. J. Neurosci. Res. 85, 525-535. doi: 10.1002/jnr.21139

Aliaga, E. E., Mendoza, I., and Tapia-Arancibia, L. (2009). Distinct subcellular localization of BDNF transcripts in cultured hypothalamic neurons and modification by neuronal activation. J. Neural Transm. 116, 23-32. doi: 10.1007/s00702-008-0159-8

Allen, M., Bird, C., Feng, W., Liu, G., Li, W., Perrone-Bizzozero, N. I., et al. (2013). HuD promotes BDNF expression in brain neurons via selective stabilization of the BDNF long 3'UTR mRNA. PLOS ONE 8:e55718. doi: 10.1371/journal.pone.0055718

An, J. J., Gharami, K., Liao, G. Y., Woo, N. H., Lau, A. G., Vanevski, F., et al. (2008). Distinct role of long 3' UTR BDNF mRNA in spine morphology and synaptic plasticity in hippocampal neurons. Cell 134, 175-187. doi: 10.1016/j.cell.2008.05.045

Antic, D., and Keene, J. D. (1998). Messenger ribonucleoprotein complexes containing human ELAV proteins: interactions with cytoskeleton and translational apparatus. J. Cell Sci. 111(Pt 2), 183-197.

Baj, G., Del Turco, D., Schlaudraff, J., Torelli, L., Deller, T., and Tongiorgi, E. (2013). Regulation of the spatial code for BDNF mRNA isoforms in the rat hippocampus following pilocarpine-treatment: a systematic analysis using laser microdissection and quantitative real-time PCR. Hippocampus 23, 413-423. doi: 10.1002/hipo. 22100

Baj, G., Leone, E., Chao, M. V., and Tongiorgi, E. (2011). Spatial segregation of BDNF transcripts enables BDNF to differentially shape distinct dendritic compartments. Proc. Natl. Acad. Sci. U.S.A. 108, 16813-16818. doi: 10.1073/pnas. 1014168108

Bernd, P. (2008). The role of neurotrophins during early development. Gene Expr. 14, 241-250. doi: 10.3727/105221608786883799

Chiaruttini, C., Sonego, M., Baj, G., Simonato, M., and Tongiorgi, E. (2008). BDNF mRNA splice variants display activity-dependent targeting to distinct hippocampal laminae. Mol. Cell. Neurosci. 37, 11-19. doi: 10.1016/j.mcn.2007.08.011

Chiaruttini, C., Vicario, A., Li, Z., Baj, G., Braiuca, P., Wu, Y., et al. (2009). Dendritic trafficking of BDNF mRNA is mediated by translin and blocked by the G196A (Val66Met) mutation. Proc. Natl. Acad. Sci. U.S.A. 106, 1648116486. doi: 10.1073/pnas.0902833106

Darnell, J. C., Jensen, K. B., Jin, P., Brown, V., Warren, S. T., and Darnell, R. B. (2001). Fragile X mental retardation protein targets $G$ quartet mRNAs important for neuronal function. Cell 107, 489-499. doi: 10.1016/S00928674(01)00566-9

Davidovic, L., Navratil, V., Bonaccorso, C. M., Catania, M. V., Bardoni, B., and Dumas, M. E. (2011). A metabolomic and systems biology perspective on the brain of the fragile X syndrome mouse model. Genome Res. 21, 2190-2202. doi: $10.1101 /$ gr.116764.110

Dictenberg, J. B., Swanger, S. A., Antar, L. N., Singer, R. H., and Bassell, G. J. (2008). A direct role for FMRP in activity-dependent dendritic mRNA transport links filopodial-spine morphogenesis to fragile X syndrome. Dev. Cell 14, 926-939. doi: 10.1016/j.devcel.2008.04.003

Edbauer, D., Neilson, J. R., Foster, K. A., Wang, C. F., Seeburg, D. P., Batterton, M. N., et al. (2010). Regulation of synaptic structure and function by FMRPassociated microRNAs miR-125b and miR-132. Neuron 65, 373-384. doi: 10.1016/j.neuron.2010.01.005

El Idrissi, A., Ding, X. H., Scalia, J., Trenkner, E., Brown, W. T., and Dobkin, C. (2005). Decreased GABA(A) receptor expression in the seizure-prone fragile $X$ mouse. Neurosci. Lett. 377, 141-146. doi: 10.1016/j.neulet.2004.11.087

Fioriti, L., Myers, C., Huang, Y. Y., Li, X., Stephan, J. S., Trifilieff, P., et al. (2015). The persistence of hippocampal-based memory requires protein synthesis

\section{SUPPLEMENTARY MATERIAL}

The Supplementary Material for this article can be found online at: http://journal.frontiersin.org/article/10.3389/fnmol. 2015.00062

mediated by the prion-like protein CPEB3. Neuron 86, 1433-1448. doi: 10.1016/j.neuron.2015.05.021

Fukuchi, M., and Tsuda, M. (2010). Involvement of the 3'-untranslated region of the brain-derived neurotrophic factor gene in activity-dependent mRNA stabilization. J. Neurochem. 115, 1222-1233. doi: 10.1111/j.14714159.2010.07016.x

Gao, F. B., and Keene, J. D. (1996). Hel-N1/Hel-N2 proteins are bound to poly $(\mathrm{A})+$ mRNA in granular RNP structures and are implicated in neuronal differentiation. J. Cell Sci. 109(Pt 3), 579-589.

Gharami, K., and Das, S. (2014). BDNF local translation in viable synaptosomes: implication in spine maturation. Neurochem. Int. 69, 28-34. doi: 10.1016/j.neuint.2014.02.009

Gorski, J. A., Zeiler, S. R., Tamowski, S., and Jones, K. R. (2003). Brain-derived neurotrophic factor is required for the maintenance of cortical dendrites. J. Neurosci. 23, 6856-6865.

Huang, Y. S., Jung, M. Y., Sarkissian, M., and Richter, J. D. (2002). N-methyl$\mathrm{D}$-aspartate receptor signaling results in Aurora kinase-catalyzed CPEB phosphorylation and alpha CaMKII mRNA polyadenylation at synapses. EMBO J. 21, 2139-2148. doi: 10.1093/emboj/21.9.2139

Huang, Y. S., Kan, M. C., Lin, C. L., and Richter, J. D. (2006). CPEB3 and CPEB4 in neurons: analysis of RNA-binding specificity and translational control of AMPA receptor GluR2 mRNA. EMBO J. 25, 4865-4876. doi: 10.1038/sj.emboj.7601322

Keene, J. D., and Tenenbaum, S. A. (2002). Eukaryotic mRNPs may represent posttranscriptional operons. Mol. Cell 9, 1161-1167. doi: 10.1016/S10972765(02)00559-2

Knowles, R. B., and Kosik, K. S. (1997). Neurotrophin-3 signals redistribute RNA in neurons. Proc. Natl. Acad. Sci. U.S.A. 94, 14804-14808. doi: 10.1073/pnas.94.26.14804

Ladd, A. N., Charlet, N., and Cooper, T. A. (2001). The CELF family of RNA binding proteins is implicated in cell-specific and developmentally regulated alternative splicing. Mol. Cell. Biol. 21, 1285-1296. doi: 10.1128/MCB.21.4.1285-1296.2001

Leal, G., Comprido, D., and Duarte, C. B. (2014). BDNF-induced local protein synthesis and synaptic plasticity. Neuropharmacology 76(Pt C), 639-656. doi: 10.1016/j.neuropharm.2013.04.005

Lein, E. S., Hohn, A., and Shatz, C. J. (2000). Dynamic regulation of BDNF and NT3 expression during visual system development. J. Comp. Neurol. 420, 1-18. doi: 10.1002/(SICI)1096-9861(20000424)420:1 < 1::AID-CNE1>3.0.CO;2-H

Lim, C. S., and Alkon, D. L. (2012). Protein kinase C stimulates HuD-mediated mRNA stability and protein expression of neurotrophic factors and enhances dendritic maturation of hippocampal neurons in culture. Hippocampus 22, 2303-2319. doi: 10.1002/hipo.22048

Lindholm, D., Da Penha Berzaghi, M., Cooper, J., Thoenen, H., and Castren, E. (1994). Brain-derived neurotrophic factor and neurotrophin-4 increase neurotrophin-3 expression in the rat hippocampus. Int. J. Dev. Neurosci. 12, 745-751. doi: 10.1016/0736-5748(94)90054-X

Louhivuori, V., Vicario, A., Uutela, M., Rantamaki, T., Louhivuori, L. M., Castren, E., et al. (2011). BDNF and TrkB in neuronal differentiation of Fmr1knockout mouse. Neurobiol. Dis. 41, 469-480. doi: 10.1016/j.nbd.2010.10.018

Martin, K. C., and Ephrussi, A. (2009). mRNA localization: gene expression in the spatial dimension. Cell 136, 719-730. doi: 10.1016/j.cell.2009.01.044

McAllister, A. K., Katz, L. C., and Lo, D. C. (1997). Opposing roles for endogenous BDNF and NT-3 in regulating cortical dendritic growth. Neuron 18, 767-778. doi: 10.1016/S0896-6273(00)80316-5

Moraes, K. C., Wilusz, C. J., and Wilusz, J. (2006). CUG-BP binds to RNA substrates and recruits PARN deadenylase. RNA 12, 1084-1091. doi: 10.1261/rna.59606

Morgan, M., Iaconcig, A., and Muro, A. F. (2010). CPEB2, CPEB3 and CPEB4 are coordinately regulated by miRNAs recognizing conserved binding sites in paralog positions of their 3'-UTRs. Nucleic Acids Res. 38, 7698-7710. doi: $10.1093 /$ nar/gkq635 
Mori, D., Sasagawa, N., Kino, Y., and Ishiura, S. (2008). Quantitative analysis of CUG-BP1 binding to RNA repeats. J. Biochem. 143, 377-383. doi: $10.1093 / \mathrm{jb} / \mathrm{mvm} 230$

Mori, Y., Imaizumi, K., Katayama, T., Yoneda, T., and Tohyama, M. (2000). Two cis-acting elements in the 3' untranslated region of alpha-CaMKII regulate its dendritic targeting. Nat. Neurosci. 3, 1079-1084. doi: 10.1038/80591

Oe, S., and Yoneda, Y. (2010). Cytoplasmic polyadenylation element-like sequences are involved in dendritic targeting of BDNF mRNA in hippocampal neurons. FEBS Lett. 584, 3424-3430. doi: 10.1016/j.febslet.2010.06.040

Paillard, L., Legagneux, V., and Beverley Osborne, H. (2003). A functional deadenylation assay identifies human CUG-BP as a deadenylation factor. Biol. Cell 95, 107-113. doi: 10.1016/S0248-4900(03)00010-8

Pattabiraman, P. P., Tropea, D., Chiaruttini, C., Tongiorgi, E., Cattaneo, A., and Domenici, L. (2005). Neuronal activity regulates the developmental expression and subcellular localization of cortical BDNF mRNA isoforms in vivo. Mol. Cell. Neurosci. 28, 556-570. doi: 10.1016/j.mcn.2004.11.010

Patz, S., and Wahle, P. (2006). Developmental changes of neurotrophin mRNA expression in the layers of rat visual cortex. Eur. J. Neurosci. 24, 2453-2460. doi: 10.1111/j.1460-9568.2006.05126.x

Philips, A. V., Timchenko, L. T., and Cooper, T. A. (1998). Disruption of splicing regulated by a CUG-binding protein in myotonic dystrophy. Science 280, 737-741. doi: 10.1126/science.280.5364.737

Pruunsild, P., Kazantseva, A., Aid, T., Palm, K., and Timmusk, T. (2007). Dissecting the human BDNF locus: bidirectional transcription, complex splicing, and multiple promoters. Genomics 90, 397-406. doi: 10.1016/j.ygeno.2007.05.004

Raju, C. S., Fukuda, N., Lopez-Iglesias, C., Goritz, C., Visa, N., and Percipalle, P. (2011). In neurons, activity-dependent association of dendritically transported mRNA transcripts with the transacting factor CBF-A is mediated by A2RE/RTS elements. Mol. Biol. Cell 22, 1864-1877. doi: 10.1091/mbc.E10-11-0904

Ratti, A., Fallini, C., Cova, L., Fantozzi, R., Calzarossa, C., Zennaro, E., et al. (2006). A role for the ELAV RNA-binding proteins in neural stem cells: stabilization of Msi1 mRNA. J. Cell Sci. 119, 1442-1452. doi: 10.1242/jcs.02852

Righi, M., Tongiorgi, E., and Cattaneo, A. (2000). Brain-derived neurotrophic factor (BDNF) induces dendritic targeting of BDNF and tyrosine kinase B mRNAs in hippocampal neurons through a phosphatidylinositol-3 kinasedependent pathway. J. Neurosci. 20, 3165-3174.

Rodriguez, A. J., Czaplinski, K., Condeelis, J. S., and Singer, R. H. (2008). Mechanisms and cellular roles of local protein synthesis in mammalian cells. Curr. Opin. Cell Biol. 20, 144-149. doi: 10.1016/j.ceb.2008.02.004

Rozhdestvensky, T. S., Kopylov, A. M., Brosius, J., and Huttenhofer, A. (2001). Neuronal BC1 RNA structure: evolutionary conversion of a tRNA(Ala) domain into an extended stem-loop structure. RNA 7, 722-730. doi: $10.1017 /$ S1355838201002485

Salehi-Ashtiani, K., Luptak, A., Litovchick, A., and Szostak, J. W. (2006). A genomewide search for ribozymes reveals an HDV-like sequence in the human CPEB3 gene. Science 313, 1788-1792. doi: 10.1126/science.1129308

Savkur, R. S., Philips, A. V., and Cooper, T. A. (2001). Aberrant regulation of insulin receptor alternative splicing is associated with insulin resistance in myotonic dystrophy. Nat. Genet. 29, 40-47. doi: 10.1038/ng704

Severt, W. L., Biber, T. U., Wu, X., Hecht, N. B., Delorenzo, R. J., and Jakoi, E. R. (1999). The suppression of testis-brain RNA binding protein and kinesin heavy chain disrupts mRNA sorting in dendrites. J. Cell Sci. 112(Pt 21), 3691-3702.

Sharma, A., Hoeffer, C. A., Takayasu, Y., Miyawaki, T., Mcbride, S. M., Klann, E., et al. (2010). Dysregulation of mTOR signaling in fragile $\mathrm{X}$ syndrome. J. Neurosci. 30, 694-702. doi: 10.1523/JNEUROSCI.3696-09.2010
Siepel, A., Bejerano, G., Pedersen, J. S., Hinrichs, A. S., Hou, M., Rosenbloom, K., et al. (2005). Evolutionarily conserved elements in vertebrate, insect, worm, and yeast genomes. Genome Res. 15, 1034-1050. doi: 10.1101/gr.3715005

Soule, J., Messaoudi, E., and Bramham, C. R. (2006). Brain-derived neurotrophic factor and control of synaptic consolidation in the adult brain. Biochem. Soc. Trans. 34, 600-604. doi: 10.1042/BST0340600

Steward, O., and Schuman, E. M. (2001). Protein synthesis at synaptic sites on dendrites. Annu. Rev. Neurosci. 24, 299-325. doi: 10.1146/annurev.neuro.24.1.299

Timchenko, N. A., Welm, A. L., Lu, X., and Timchenko, L. T. (1999). CUG repeat binding protein (CUGBP1) interacts with the 5 ' region of $\mathrm{C} / \mathrm{EBPbeta}$ mRNA and regulates translation of C/EBPbeta isoforms. Nucleic Acids Res. 27, 4517-4525. doi: 10.1093/nar/27.22.4517

Timmusk, T., Palm, K., Metsis, M., Reintam, T., Paalme, V., Saarma, M., et al. (1993). Multiple promoters direct tissue-specific expression of the rat BDNF gene. Neuron 10, 475-489. doi: 10.1016/0896-6273(93)90335-O

Tongiorgi, E. (2008). Activity-dependent expression of brain-derived neurotrophic factor in dendrites: facts and open questions. Neurosci. Res. 61, 335-346. doi: 10.1016/j.neures.2008.04.013

Tongiorgi, E., Armellin, M., Giulianini, P. G., Bregola, G., Zucchini, S., Paradiso, B., et al. (2004). Brain-derived neurotrophic factor mRNA and protein are targeted to discrete dendritic laminas by events that trigger epileptogenesis. J. Neurosci. 24, 6842-6852. doi: 10.1523/JNEUROSCI.5471-03.2004

Tongiorgi, E., Righi, M., and Cattaneo, A. (1997). Activity-dependent dendritic targeting of BDNF and TrkB mRNAs in hippocampal neurons. J. Neurosci. 17, 9492-9505.

Tongiorgi, E., Righi, M., and Cattaneo, A. (1998). A non-radioactive in situ hybridization method that does not require RNAse-free conditions. J. Neurosci. Methods 85, 129-139. doi: 10.1016/S0165-0270(98)00123-X

Verpelli, C., Piccoli, G., Zibetti, C., Zanchi, A., Gardoni, F., Huang, K., et al. (2010). Synaptic activity controls dendritic spine morphology by modulating eEF2-dependent BDNF synthesis. J. Neurosci. 30, 5830-5842. doi: 10.1523/JNEUROSCI.0119-10.2010

Wickens, M., Bernstein, D. S., Kimble, J., and Parker, R. (2002). A PUF family portrait: 3'UTR regulation as a way of life. Trends Genet. 18, 150-157. doi: 10.1016/S0168-9525(01)02616-6

Will, T. J., Tushev, G., Kochen, L., Nassim-Assir, B., Cajigas, I. J., Tom Dieck, S., et al. (2013). Deep sequencing and high-resolution imaging reveal compartment-specific localization of Bdnf mRNA in hippocampal neurons. Sci. Signal. 6:rs16. doi: 10.1126/scisignal.2004520

Zhang, H. L., Singer, R. H., and Bassell, G. J. (1999). Neurotrophin regulation of beta-actin mRNA and protein localization within growth cones. J. Cell Biol. 147, 59-70. doi: $10.1083 / \mathrm{jcb} .147 .1 .59$

Conflict of Interest Statement: The authors declare that the research was conducted in the absence of any commercial or financial relationships that could be construed as a potential conflict of interest.

Copyright (c) 2015 Vicario, Colliva, Ratti, Davidovic, Baj, Gricman, Colombrita, Pallavicini, Jones, Bardoni and Tongiorgi. This is an open-access article distributed under the terms of the Creative Commons Attribution License (CC BY). The use, distribution or reproduction in other forums is permitted, provided the original author(s) or licensor are credited and that the original publication in this journal is cited, in accordance with accepted academic practice. No use, distribution or reproduction is permitted which does not comply with these terms. 